\title{
A Novel Analytical Solution for the Brazilian Test with Loading Arcs
}

\author{
R. Gutiérrez-Moizant ${ }^{1},{ }^{1}$ M. Ramírez-Berasategui, ${ }^{1}$ S. Santos-Cuadros, ${ }^{1}$ \\ and C. C. García-Fernández ${ }^{2}$ \\ ${ }^{1}$ Mechanical Engineering Department, Universidad Carlos III de Madrid, Leganés, Madrid 28911, Spain \\ ${ }^{2}$ Department of Mining Exploitation and Prospecting, Universidad de Oviedo, Oviedo, Asturias 33004, Spain
}

Correspondence should be addressed to R. Gutiérrez-Moizant; ragutier@ing.uc3m.es

Received 1 July 2019; Revised 24 September 2019; Accepted 28 September 2019; Published 28 February 2020

Academic Editor: John D. Clayton

Copyright (C) 2020 R. Gutiérrez-Moizant et al. This is an open access article distributed under the Creative Commons Attribution License, which permits unrestricted use, distribution, and reproduction in any medium, provided the original work is properly cited.

\begin{abstract}
This research study presents a new theoretical model to calculate the indirect tensile strength for the Brazilian disk with loading arcs, based on numerical simulations, two-dimensional elasticity theory, and Griffith failure criterion. The new expression incorporates a no uniform contact pressure distribution determined by the results of the simulations with the finite element method. A computational experiment design has been developed to test the accuracy of the predictions made with the proposed model. This study demonstrates that the stresses predicted with the new model are closer to those determined by the finite element models than other theoretical solutions available in the literature. Additionally, a comparative analysis with experimental results obtained by other authors also indicates that the new model provides a more accurate magnitude of the indirect tensile strength.
\end{abstract}

\section{Introduction}

The Brazilian test is an indirect procedure used to determine the tensile strength in rocks and concrete materials and is based on the assumption of an elastic and homogeneous behaviour of the materials and two-dimensional elastic theory [1-3]. This technique provides a practical and less expensive alternative test compared to the direct tensile test $[4,5]$. Unlike the classical uniaxial test, it is not necessary to attach the specimen ends to the loading device, thereby avoiding premature failure during the test setup $[6,7]$. In the Brazilian test, a circular disk sample extracted from the material is diametrically compressed until the transverse stress normal to the loading diameter causes specimen failure. According to the expression adopted by international standards [1-3], the maximum tensile stress is in the centre of the disk, so it is assumed that crack initiation occurs in this area. The International Society for Rock Mechanics (ISRM) [1] suggested using two steel jaws with a face radius 1.5 times that of the specimen radius (Figure 1(a)) in order to obtain a final contact angle between the tested disk and the loading device of approximately $10^{\circ}$. Therefore, the indirect tensile strength can be calculated with the following equation:

$$
\sigma_{t}=\frac{P}{\pi R t}
$$

The failure procedure in the Brazilian test is generally analysed by the Griffith criterion [8]. According to this theory, crack initiation has to occur in the centre of the disk to ensure that the maximum transverse stress produced at this location corresponds to the uniaxial tensile strength [9]. Nevertheless, several studies have observed a premature failure of the tested disk close to the loading zone, which invalidates the test for determining the tensile strength [9-13]. Therefore, the effectiveness of the classical Brazilian test adopted by the ISRM is not guaranteed, as the Griffith criterion is not fulfilled [8].

To reduce the stress concentration on the loading zone, Jaeger and Hoskins [14] proposed using loading arcs (Figure 1(c)) instead of classical ISRM jaws, in order to allow for better control of the contact angle. Years later, Mellor 


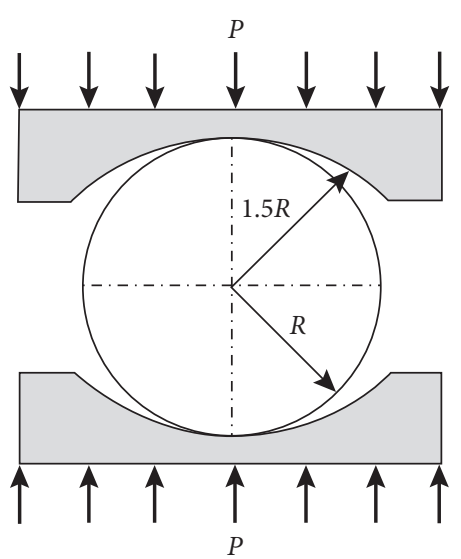

(a)

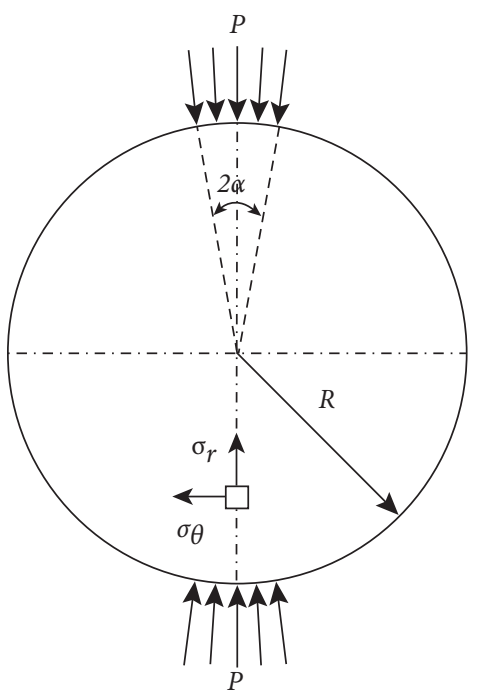

(b)

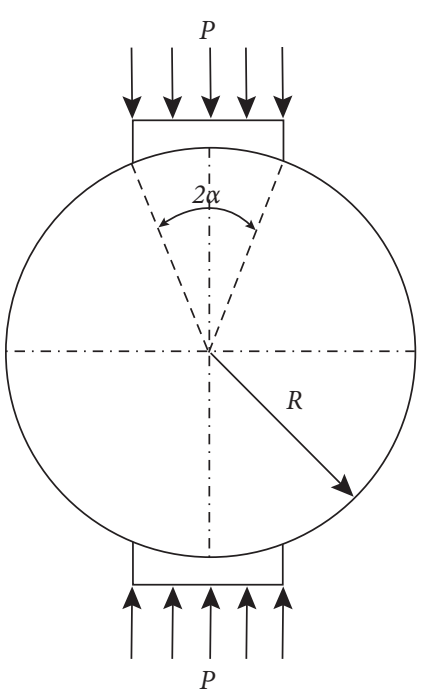

(c)

FIGURE 1: (a) Brazilian test with classical jaws. (b) Disk sample subjected to radial uniform distributed loads over a finite arc. (c) Brazilian test with loading arcs.

and Hawkes [15] criticized this loading configuration, claiming that the arc ends could penetrate the sample and that the central disk failure was not guaranteed. However, $\mathrm{Yu}$ et al. [16] experimentally observed that when the contact angle between the disk sample and the loading device was larger than $20^{\circ}$, the crack initiation was well defined, and the variability of the experimental tensile strength value was small. Additionally, Erarslan et al. [11] proposed the use of loading arcs, demonstrating that they could produce a better measure of the tensile strength if the procedure is carefully performed. According to these authors, the loading arc method ensures the central failure of the disk for $20^{\circ} \leq 2 \alpha \leq 30^{\circ}$. To prove this, they compared the experimental results with the numerical models and observed that the crack moves towards the centre of the disk as the contact angle increases.
The contact angle in the Brazilian test performed with loading arcs (Figure 1(c)) is distributed over a finite length. Consequently, the classical expression initially proposed by the International Society of Rock Mechanics (ISRM) [1] no longer seems valid.

The theoretical stress expression used by Erarslan et al. [11] is based on the Hondros analytical solution [17]. This solution supposes that a uniform pressure is applied radially over a short finite arc (Figure 1(b)), under the assumption of isotropic and homogeneous material behaviour of the disk and the plane-stress condition.

According to Hondros [17], the complete stress field along the vertical diameter of the disk shown in Figure 1(b) can be calculated as follows:

$$
\begin{aligned}
& \sigma_{\theta}=\frac{P}{\pi R t \alpha}\left\{\frac{\left[1-(r / R)^{2}\right] \sin 2 \alpha}{1-2(r / R)^{2} \cos 2 \alpha+(r / R)^{4}}-\tan ^{-1}\left[\frac{1+(r / R)^{2}}{1-(r / R)^{2}} \tan \alpha\right]\right\}, \\
& \sigma_{r}=-\frac{P}{\pi R t \alpha}\left\{\frac{\left[1-(r / R)^{2}\right] \sin 2 \alpha}{1-2(r / R)^{2} \cos 2 \alpha+(r / R)^{4}}+\tan ^{-1}\left[\frac{1+(r / R)^{2}}{1-(r / R)^{2}} \tan \alpha\right]\right\}, \\
& \tau_{r \theta}=0,
\end{aligned}
$$

where $P$ is the radial load applied over a finite arc of the disk, $R$ is the radius of the disk sample, $r$ is the vertical distance of the point measured from the centre, $t$ is the thickness of the disk, and $2 \alpha$ is the angle of the finite loading arc.

Experimentally, it is difficult to know the real pressure distribution in the contact surfaces between the loading device and the disk. Analytical studies have been performed to analyse the influence of the contact pressure distribution (parabolic, uniform, and sinusoidal) to theoretically predict the splitting tensile stress $[18,19]$. It was concluded that the effect of the contact pressure distribution could be negligible at points far from the contact area. The fact that the stress field at the centre of the disk is quite insensitive to the loading pressure distribution does not guarantee the validity 
of the results obtained from a statistical point of view. A recent research work indicated that the distribution of the contact load is not uniform and that the statistical validity of the prediction, based on the Hondros assumption [17], depends on the loading arc length [20].

The models developed in the engineering field usually intend to reproduce the case under study with the required accuracy. Therefore, validation methodology can be developed with a predefined acceptable error due to simplification of either the model or some boundary conditions that are not taken into account [21]. Therefore, the goal of the statistical model validation is to measure if the mathematical model is successfully defined by quantifying the quality of the predictive response of the model [22].

The objective of the engineering models is not to reproduce the physical behaviour exactly, but simply to approximate the behaviour to some acceptable level of error [21]. Once these errors have been identified, they can be incorporated into the model in order to increase the quality of the predictions and meet the requirements of the statistical validation. Therefore, the response of a statistically validated model will always be more accurate than that of another that does not comply. This is why it is important to determine the pressure distribution in the contact zone for the Brazilian test with loading arcs because with this, the predictions of the stresses in the disk can be improved.

Using a numerical approach as the finite element method, the boundary element method and the discrete element method have become essential tools for the stability analysis of rock and concrete. These tools allow for the initiation and propagation of single and multiple cracks in rock and concrete failure studies to be verified [23].

The results from several research studies performed to date show that the finite element method (FEM) can effectively recreate the indirect test in its different configurations (flat pattern, loading arc, and classical Brazilian). Indriyantho and Nuroji [6] developed a finite element programme that is able to accurately reproduce the load-displacement curves of the concrete under the Brazilian test. The author recommended using a planestrain model instead of a plane-stress model because the first more closely resembles the experimental data. Erarslan et al. [11] implemented a numerical finite element approach called rock fracture process analysis (RFPA) to corroborate the fracturing process in a Brazilian disk under different loading device configurations. This approach allows for the heterogeneity of the mechanical properties of rocks to be modelled as defined by probability density functions. Erarslan et al. [11] concluded that the numerical simulations correctly represent the real fracture behaviour of the rocks tested. Komurlu et al. [24] realized an extensive experimental analysis of different rock disks tested with different configurations of the steel jaws. They observed that the standard jaw recommended by the ISRM sometimes causes catastrophic failure. According to these authors, the standard jaw origins scattered fractures so that the crack initiation is not clear. They also concluded that the crack initiation is difficult to determine experimentally, as was reported in other research [9]. In both studies, the finite element methods helped to check the beginning and evolution of the disk failure.

Therefore, why not use the finite element method to develop a new analytical model for indirect testing with loading arcs after the results of the simulations? It is for this reason that this method has been used in the present research to analyse the resulting pressure distribution in the contact of the loading arc with the disk. This information will allow for a new analytical model to be developed that is closer to the behaviour observed in the virtual tests for the contact angles recommended by Erarslan et al. [11].

In this research work, several virtual tests have been performed in order to do the following:

(i) Verify through numerical simulations the influence of the friction between the contact surfaces by means of a sensitivity analysis for the loading device as recommended by Erarslan et al. [11]. This will allow for checking the areas of the disk that are more affected by the value of friction, and its compatibility with the observations of other authors $[25,26]$.

(ii) Check the influence of the elastic properties of the disk material and the friction in the indirect tensile strength for loading arcs of $20^{\circ}, 25^{\circ}$, and $30^{\circ}$. This allows for analysing what loading conditions are less sensitive to the randomness of the elastic properties and can guarantee the smallest experimental deviation.

(iii) Quantify the differences between the new model proposed and the Hondros analytical solution, using the results of the virtual Brazilian tests in terms of the Griffith equivalent stress, considering the uncertainty in the models. This section will allow for quantifying the degree of success of the theoretical models considered for different material properties and contact angles.

(iv) Compare the new analytical solution with the experimental results from other authors so that it is possible to demonstrate its higher accuracy without being affected by the length of the contact arc.

The present research work tries to minimize the highly stochastic nature of this type of test through the development of a model that best represents the Brazilian test in the area of potential failure and therefore allows for a greater degree of confidence in the magnitude of the indirect tensile strength.

\section{Contact of Two-Dimensional Bodies}

The elastic compression of a disk due to diametrically opposed concentrated loads was first developed by Timoshenko [27]. If the contact between the surfaces shown in Figure 2 is small $(a \ll R)$, the stress field at point $M$ inside the compressed disk can be calculated as the superposition of the following contributions [28]: 


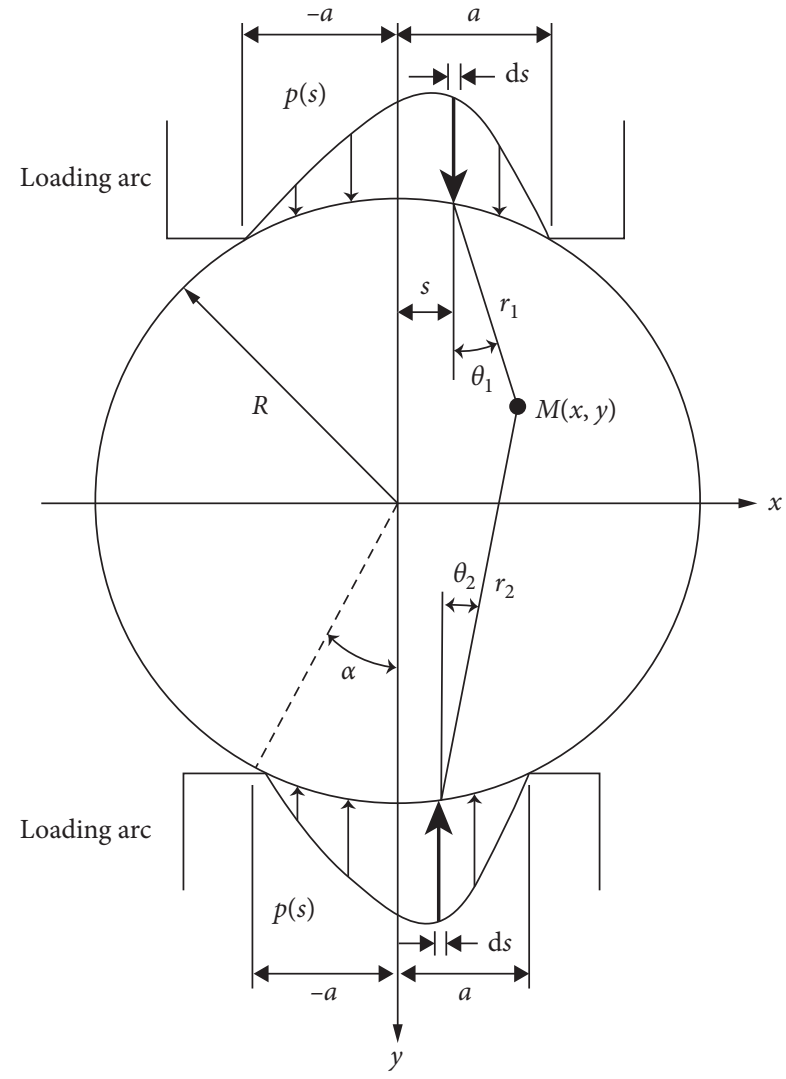

FIgURE 2: Contact of the two-dimensional bodies.

(i) The stress state due to the contact pressure distribution between the top and the bottom compression devices on the disk.

(ii) A uniform biaxial stress (3) applied so that the boundary of the disk is free from any stress [27]:

$$
\sigma_{u}=\frac{P}{\pi R t}
$$

where $P$ is the applied load and $R$ and $t$ are the radius and the thickness of the disk, respectively.

Figure 2 represents the contribution of the stress due to the normal pressure $p(s)$, considering that the effect of the friction on the contact area can be neglected. The pressure on a portion of the contact surface, $\mathrm{d} s$, located at a distance $s$ from the vertical radius, can be calculated as the quotient of a concentrated force $p$ and $\mathrm{d} s$. These concentrated forces produce two simple radial distributions at point $M$ according to directions $r_{1}$ and $r_{2}$. They can be expressed in rectangular coordinates by

$\sigma_{x}=\sigma_{r 1} \sin ^{2} \theta_{1}+\sigma_{r 2} \sin ^{2} \theta_{2}=-\frac{2 P}{\pi}\left[\frac{x^{2} y_{1}}{\left(x^{2}+y_{1}^{2}\right)^{2}}+\frac{x^{2} y_{2}}{\left(x^{2}+y_{2}^{2}\right)^{2}}\right]$,

$\sigma_{y}=\sigma_{r 1} \cos ^{2} \theta_{1}+\sigma_{r 2} \cos ^{2} \theta_{2}=-\frac{2 P}{\pi}\left[\frac{y_{1}^{3}}{\left(x^{2}+y_{1}^{2}\right)^{2}}+\frac{y_{2}^{3}}{\left(x^{2}+y_{2}^{2}\right)^{2}}\right]$,

$$
\begin{aligned}
\tau_{x y r} & =\sigma_{r 1} \sin \theta_{1} \cos \theta_{1}+\sigma_{r 2} \sin \theta_{2} \cos \theta_{2} \\
& =-\frac{2 P}{\pi}\left[\frac{x y_{1}^{2}}{\left(x^{2}+y_{1}^{2}\right)^{2}}+\frac{x y_{2}^{2}}{\left(x^{2}+y_{2}^{2}\right)^{2}}\right] .
\end{aligned}
$$

Replacing $x$ by $(x-s)$ in equations (4)-(6) and integrating over the loaded surface, it is possible to obtain the stress field in point $M$ due to the two simple radial distributions created by the normal pressure $p(s)$ on both loading arcs.

$$
\begin{aligned}
\sigma_{x}= & -\frac{2 y_{1}}{\pi} \int_{-a}^{a} \frac{p(s)(x-s)^{2}}{\left[(x-s)^{2}+y_{1}^{2}\right]^{2}} \mathrm{~d} s \\
& -\frac{2 y_{2}}{\pi} \int_{-a}^{a} \frac{p(s)(x-s)^{2}}{\left[(x-s)^{2}+y_{2}^{2}\right]^{2}} \mathrm{~d} s, \\
\sigma_{y}= & -\frac{2 y_{1}^{3}}{\pi} \int_{-a}^{a} \frac{p(s)}{\left[(x-s)^{2}+y_{1}^{2}\right]^{2}} \mathrm{~d} s \\
& -\frac{2 y_{2}^{3}}{\pi} \int_{-a}^{a} \frac{p(s)}{\left[(x-s)^{2}+y_{2}^{2}\right]^{2}} \mathrm{~d} s, \\
\tau_{x y}= & -\frac{2 y_{1}^{2}}{\pi} \int_{-a}^{a} \frac{p(s)(x-s)}{\left[(x-s)^{2}+y_{1}^{2}\right]^{2}} \mathrm{~d} s \\
& -\frac{2 y_{2}^{2}}{\pi} \int_{-a}^{a} \frac{p(s)(x-s)}{\left[(x-s)^{2}+y_{2}^{2}\right]^{2}} \mathrm{~d} s .
\end{aligned}
$$

If the distribution $p(s)$ is known, the final stresses inside the compressed disk can be deduced by the integration of the previous expressions together with the uniform biaxial tension given by (3).

\section{Finite Element Models}

To characterize the load distribution in the contact area, a set of virtual Brazilian tests with loading arcs (Figure 3) were performed in the commercial software Abaqus as two-dimensional plane-strain models considering the state of the art $[6,11]$. An elastic and homogeneous behaviour of the material properties was assumed. The contact between the loading arcs and the disk was simulated using a surface-tosurface contact discretization. The approach considers the shape of the contact geometries and provides more accurate results than a node-to-surface formulation if the surface geometry is well characterized, i.e., without irregularities, such as crests and troughs [29]. The contact conditions are defined over a finite region instead of at each node, which tends to alleviate contact problems as the master surface penetrating the slave surface. This is suitable in situations in which the normal direction of the surfaces in contact are opposite, as is the case of the Brazilian disk with the loading device. For its implementation, it is necessary to identify a master surface, generally the strongest surface, which in our case study is the loading arcs, and a slave surface, which is the Brazilian disk. The finite-sliding contact formulation was selected in order to continually update which part of the 


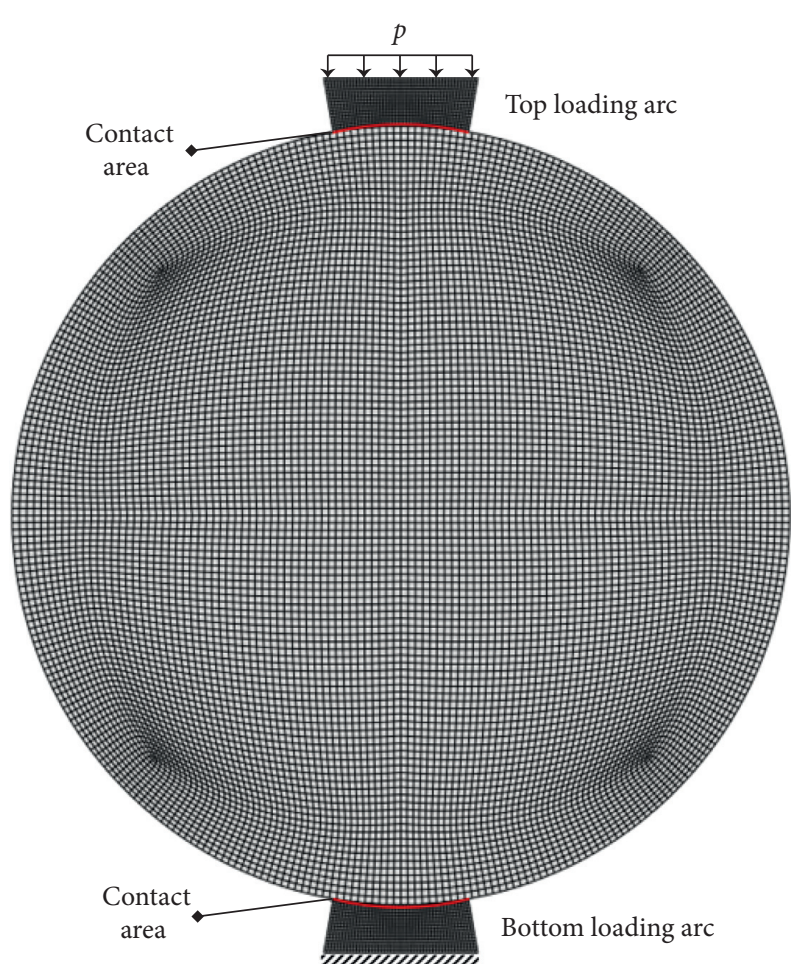

Figure 3: Numerical Brazilian test with loading arcs.

master surface is in contact with each slave node as the disk is compressed. Following the recommendation of the Abaqus documentation, a minimum tolerance of $0 \mathrm{~mm}$ for the surfaces in contact was specified. This avoids possible converge problems due to overclosed nodes [29].

The loading arcs were modelled with a typical steel Young modulus of $210 \mathrm{GPa}$ and a Poisson ratio of 0.33 . The loading device materials guarantee the stiffness of the loading device and are in agreement with the requirement given by the ISRM [1]. The disk was meshed with 4 -node bilinear plane-strain quadrilateral elements $0.5 \mathrm{~mm}$ of size. The final element size used guarantees the convergence of the solution with respect to mesh refinement. The loading arcs were modelled with the same element type as the disk but with a size of $0.2 \mathrm{~mm}$, in order to obtain a high number of nodes to analyse the contact pressure distribution of the numerical solutions.

A uniform pressure of $35 \mathrm{MPa}$ was applied to the flat surface of the top loading arc, while the bottom was completely fixed in the lower face. The disk has a diameter of $58 \mathrm{~mm}$ and a thickness of $29.7 \mathrm{~mm}$ and is based on the geometry commonly used in other studies [1, 11, 26, 30, 31].

A sensitivity analysis was performed with the numerical Brazilian with loading arcs of $20^{\circ}, 25^{\circ}$, and $30^{\circ}$ in order to verify the influence of the friction between the contact surfaces on the loading radius of the disk.

To check the stability of the tensile stress results in the centre of the disk and quantify their differences with respect to the theoretical solutions, a response surface methodology was applied to the virtual Brazilian test. The design of the numerical experiments was performed considering the variation in the material properties of the Brazilian disk as
Young's modulus $E(22 \mathrm{GPa}-70 \mathrm{GPa})$, Poisson's ratio $v$ (0.15-0.33), and different friction coefficient values $\mu$ $(0.2-0.5)$ between the contact surfaces. The computational experimental design was constructed according to the different rocks and concrete materials found in the literature review [24, 30-35]. These parameters were varied up to five levels using a central composite design (CCD). For the analysis, the elastic properties of the loading arcs were not modified.

Table 1 shows the computational experimental combinations for the Brazilian disk conducted in this research work. The computational experiment was implemented for contact angles of $20^{\circ}, 25^{\circ}$, and $30^{\circ}$, generating a total of 48 simulations.

\section{Distribution of the Contact Stress Resulting from Simulation}

Ideally, the Brazilian test with loading arcs guarantees that the contact angle does not depend on the applied load and on the material properties of the loading device and the tested disk because the face radius of the loading arcs is the same that the radius of the disk. The problem is that it is complicated to know the real distribution of the contact pressure. In this situation, finite element simulations can help analyse the possible distributions under different loading boundary conditions. Figure 4 shows the final contact stress per unit length from the simulations with a frictionless loading arc of $20^{\circ}$ and $30^{\circ}$.

It should be noted that the distribution of the contact stresses shown in Figure 4 differs from all the distributions studied to date by different authors (parabolic and sinusoidal) $[18,19]$. In fact, they tend to be opposite to the distribution found in the present research work, as they are high in the centre and low in the extreme (concave). Therefore, it is important to verify how this distribution affects the theoretical stresses in the loading diameter of the disk. For this, it is necessary to find a theoretical distribution that is closer to the numerical one. Figure 4 also represents the values of the theoretical pressure calculated from a frictionless rigid flat punch (10). As seen, the rigid punch distribution presents a behaviour that is very similar to the finite elements results, except for the ends. The rigid punch distribution is defined as follows [28]:

$$
p(s)=\frac{P}{\pi t\left(a^{2}-s^{2}\right)^{1 / 2}},
$$

where $P$ is the applied load, $t$ is the disk thickness, and $a$ and $s$ are the edge and an arbitrary point position, respectively.

It is therefore be appropriate to develop a new analytical expression for the Brazilian test with loading arcs considering the punch distribution in order to verify if the accuracy of the predictions can be improved.

\section{New Analytical Expression for the Brazilian Test with Loading Arcs}

In brittle or quasi-brittle materials, such as concrete and rocks, the failure initiation is usually analysed by the Griffith 
TABLe 1: Computational experiment design of the Brazilian disk.

\begin{tabular}{lccc}
\hline Run order & Young modulus $E(\mathrm{GPa})$ & Poisson's coefficient $\nu(\mu \varepsilon / \mu \varepsilon)$ & Coefficient of friction $\mu(\mathrm{N} / \mathrm{N})$ \\
\hline 1 & 5.64 & 0.24 & 0.35 \\
2 & 22 & 0.15 & 0.50 \\
3 & 22 & 0.33 & 0.20 \\
4 & 22 & 0.15 & 0.20 \\
5 & 22 & 0.33 & 0.50 \\
6 & 46 & 0.24 & 0.35 \\
7 & 46 & 0.24 & 0.10 \\
8 & 46 & 0.24 & 0.60 \\
9 & 46 & 0.09 & 0.35 \\
10 & 46 & 0.39 & 0.35 \\
11 & 46 & 0.24 & 0.35 \\
12 & 70 & 0.15 & 0.20 \\
13 & 70 & 0.33 & 0.50 \\
14 & 70 & 0.33 & 0.20 \\
15 & 70 & 0.15 & 0.50 \\
\hline
\end{tabular}

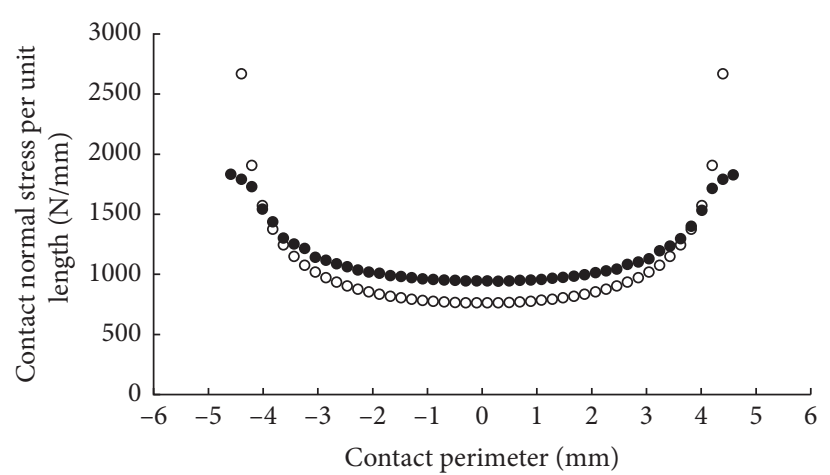

- FEM distribution

- Punch distribution

(a)

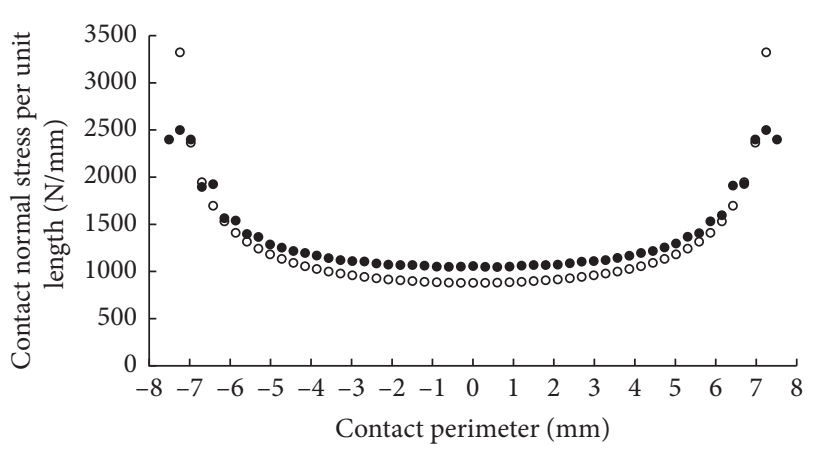

- FEM distribution

- Punch distribution

(b)

Figure 4: Contact stress distribution from the numerical Brazilian test with loading arcs. (a) $2 \alpha=20^{\circ}$. (b) $2 \alpha=30^{\circ}$.

criterion [8]. In agreement with this theory, the crack initiation in the Brazilian test has to be located in the centre of the disk to guarantee that the tensile failure corresponds to the uniaxial tensile strength. Failure begins when the equivalent Griffith stress $\sigma_{G}$ is greater than or equal to the tensile strength $\sigma_{t}$ of the brittle material.

The work performed by Satoh [36], and verified later by others authors [20,37], concludes that the predominant failure condition in this alternative test according to the Griffith criterion is $3 \sigma_{\theta}+\sigma_{r}<0$. Therefore, the tensile strength is given by the equivalent Griffith's stress [8]:

$$
\sigma_{G}=-\frac{\left(\sigma_{\theta}-\sigma_{r}\right)^{2}}{8\left(\sigma_{\theta}+\sigma_{r}\right)}
$$

In all the simulations performed, it was verified that the predominant Griffith's failure condition is $3 \sigma_{\theta}+\sigma_{r}<0$, which is in agreement with the results obtained by other researchers [36,37]. Consequently, the tensile strength has been determined with the Griffith equivalent stress (11).
Figure 5 shows the disk distribution map of the equivalent Griffith stress. This equivalent stress has been calculated by means of a routine developed in MATLAB from the stress results of the simulations for each of the nodes that make up the disk.

Figure 5 indicates that the maximum equivalent stress is located in the centre of the disk for the two analysed cases. The edges of the arcs also present a relative concentration of equivalent stress with magnitudes approximately equal to $60 \%$ and $50 \%$ of the value in the centre for angles of $20^{\circ}$ and $30^{\circ}$, respectively. It can then be expected that the crack will begin in the centre and probably propagate towards the edges of the loading arc, as was observed from previous research studies $[11,12,38]$.

According to the Griffith stresses shown in Figure 5 when a $20^{\circ}$ loading arc is used, the immediate appearance of a central crack in the entire vertical diameter of the disk can be expected because the stresses in this area are similar. On the contrary, when using a loading arc of $30^{\circ}$, the crack will be located in a smaller central area. These observations are in 


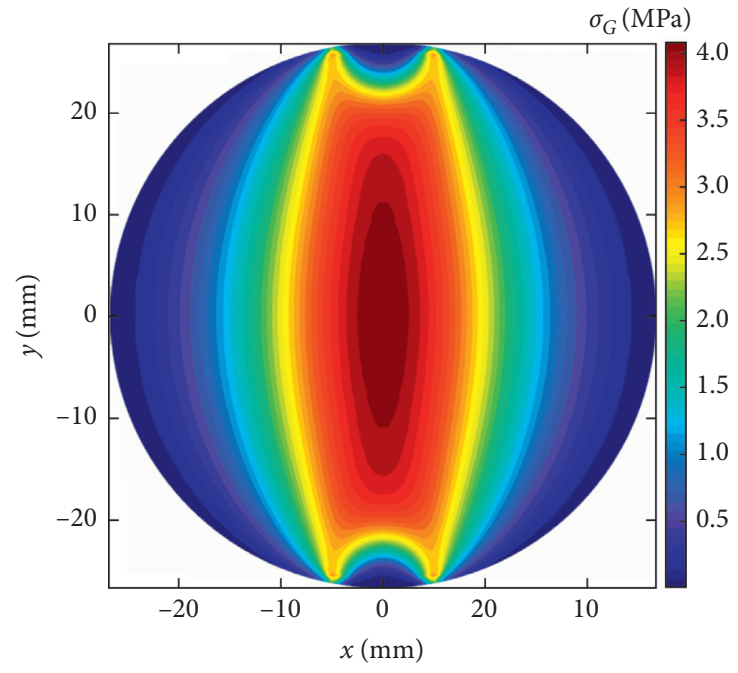

(a)

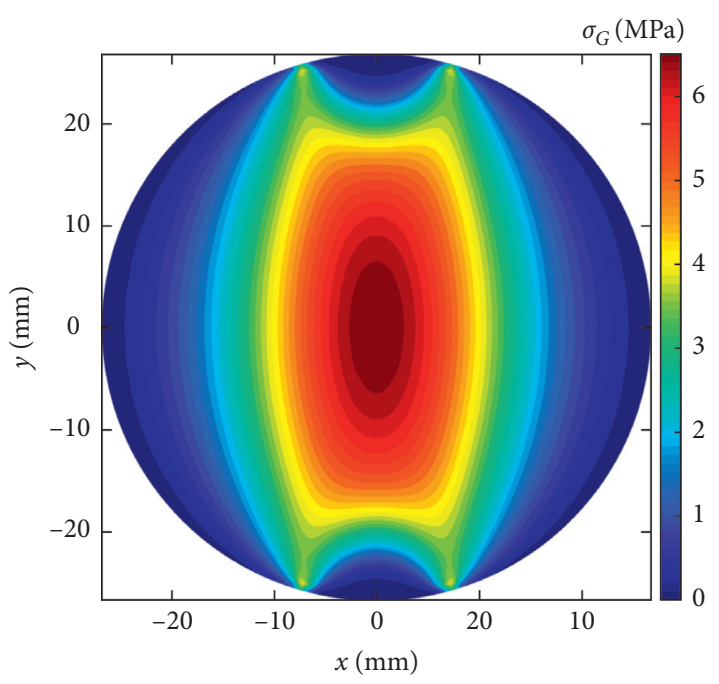

(b)

Figure 5: Equivalent Griffith stress distribution for the virtual Brazilian disk for a contact angle of: (a) $20^{\circ}$. (b) $30^{\circ}$.

agreement with the results of different research works $[11,16,24]$.

The results of the simulations indicate that higher stresses occur in the loaded vertical diameter of the disk. Therefore, the analytical solution developed in this research is restricted to the vertical diameter $(x=0)$, as it corresponds to the potential failure region. Moreover, it is also necessary to determine the influence of the tangential forces in the contact due to the friction between the loading arc and the disk in the distribution of the equivalent stresses.

Figure 6 shows the differences expressed in terms of the Griffith equivalent stress $\left(\Delta \sigma_{G}=\sigma_{G_{-} 0.75}-\sigma_{G_{-} 0}\right)$ between the numerical solution of the Brazilian disk with a coefficient of friction of $0.75\left(\sigma_{G_{-} 0.75}\right)$ and without friction $\left(\sigma_{G_{-} 0}\right)$ for the loading arcs of $20^{\circ}$ and $30^{\circ}$. The distribution of these differences provides global information of the stress behaviour on the surface of the disk but only due to variations in the friction coefficient. The difference has been obtained using an algorithm implemented in MATLAB through each nodal stress solution from the finite element simulation.

In Figure 6, it can be seen that the difference between the equivalent stresses from the simulations of models with friction 0.75 and the frictionless model is only present on the edges of the two analysed loading arcs, with a value slightly higher than $2 \mathrm{MPa}$. It has also been found that the influence of friction on the rest of the disk is negligible, not exceeding $0.5 \mathrm{MPa}$ in any case. These results justify that the new theoretical expression developed in this research work does not consider the tangential forces produced by the friction in the contact area. However, the fact that friction has a negative effect near the contact edges of the loading arcs may cause premature disk failure, unless certain precautions are taken. According to the simulation results, as the friction coefficient increases, the magnitude of the contact pressure near the edge of the loading arc also increases. Therefore, irregularities in the contact surface of both the disks and jaws (due to a poor preparation of the sample or the loading device) can favour from the development of unwanted small cracks near the edges of the contact, simultaneously with a central crack. This situation could invalidate the test results if it is not clear which of the cracks was the first to initiate.

Including equation (10) into equations (7)-(9), it is possible to determine the stress components of the radial distribution generated by the frictionless rigid punch pressure:

$$
\begin{gathered}
\sigma_{x}=-\frac{2 P y_{1}}{\pi^{2} t} \int_{-a}^{a} \frac{(x-s)^{2}}{\left(a^{2}-s^{2}\right)^{1 / 2}\left[(x-s)^{2}+y_{1}^{2}\right]^{2}} \mathrm{~d} s-\frac{2 P y_{2}}{\pi^{2} t} \int_{-a}^{a} \frac{(x-s)^{2}}{\left(a^{2}-s^{2}\right)^{1 / 2}\left[(x-s)^{2}+y_{2}^{2}\right]^{2}} \mathrm{~d} s, \\
\sigma_{y}=-\frac{2 P y_{1}^{3}}{\pi^{2} t} \int_{-a}^{a} \frac{1}{\left(a^{2}-s^{2}\right)^{1 / 2}\left[(x-s)^{2}+y_{1}^{2}\right]^{2}} \mathrm{~d} s-\frac{2 P y_{2}^{3}}{\pi^{2} t} \int_{-a}^{a} \frac{1}{\left(a^{2}-s^{2}\right)^{1 / 2}\left[(x-s)^{2}+y_{2}^{2}\right]^{2}} \mathrm{~d} s, \\
\tau_{x y}=-\frac{2 y_{1}^{2}}{\pi} \int_{-a}^{a} \frac{(x-s)}{\left(a^{2}-s^{2}\right)^{1 / 2}\left[(x-s)^{2}+y_{1}^{2}\right]^{2}} \mathrm{~d} s-\frac{2 y_{2}^{2}}{\pi} \int_{-a}^{a} \frac{(x-s)}{\left(a^{2}-s^{2}\right)^{1 / 2}\left[(x-s)^{2}+y_{2}^{2}\right]^{2}} \mathrm{~d} s,
\end{gathered}
$$




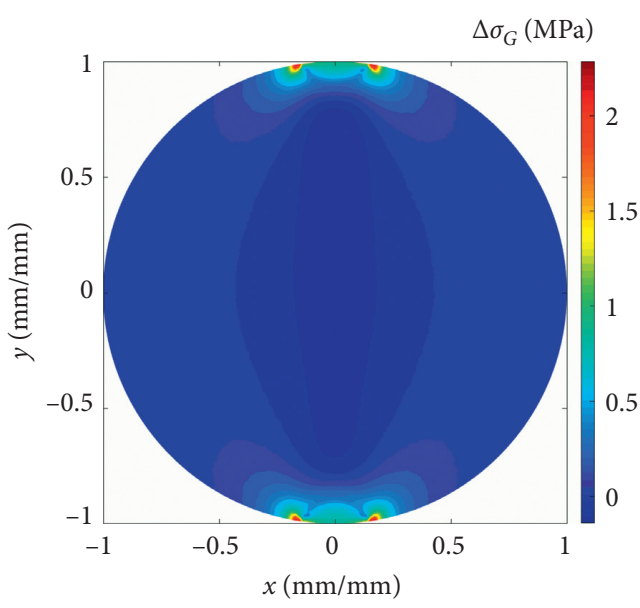

(a)

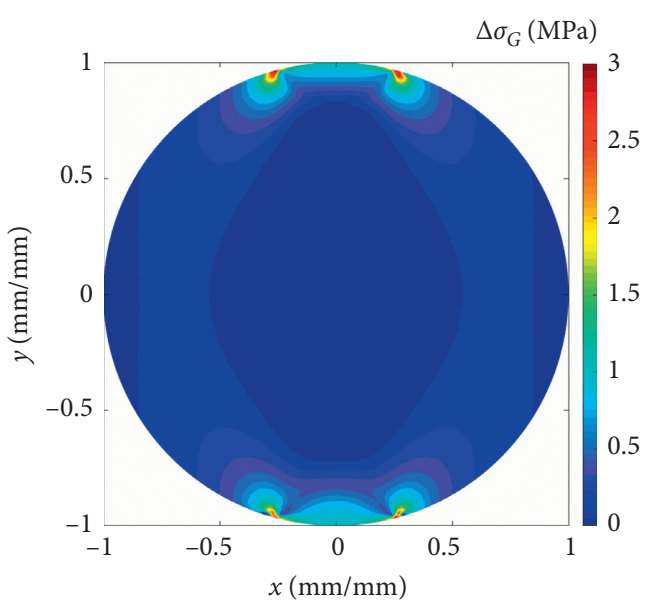

(b)

Figure 6: Equivalent Griffith stress distribution for the virtual Brazilian disk for a contact angle of: (a) $20^{\circ}$. (b) $30^{\circ}$.

where from Figure 2, we have

$$
\begin{aligned}
a & =R \alpha, \\
y_{1} & =R-r, \\
y_{2} & =R+r, \\
\rho & =\frac{r}{R} .
\end{aligned}
$$

Finally, solving the previous integrals for $x=0$ and superposing the uniform tensile stress (3), the new expressions for the calculus of the stress field for the loading diameter of the Brazilian disk with loading arcs are

$$
\begin{aligned}
& \sigma_{\theta}=\frac{P}{\pi R t}\left\{1-\alpha^{2}\left[\frac{1}{\left[\alpha^{2}+(1-\rho)^{2}\right]^{3 / 2}}+\frac{1}{\left[\alpha^{2}+(1+\rho)^{2}\right]^{3 / 2}}\right]\right\}, \\
& \sigma_{r}=\frac{P}{\pi R t}\left\{1-\left[\frac{\alpha^{2}+2(1-\rho)^{2}}{\left[\alpha^{2}+(1-\rho)^{2}\right]^{3 / 2}}+\frac{\alpha^{2}+2(1+\rho)^{2}}{\left[\alpha^{2}+(1+\rho)^{2}\right]^{3 / 2}}\right]\right\},
\end{aligned}
$$$$
\tau_{\theta r}=0
$$

Several studies have concluded that the numerical simulations correctly represent the failure initiation and propagation of the damage on the Brazilian disk $[6,11,24]$. Therefore, the new expression proposed in the actual research work, developed considering the contact stress distribution of the simulations results, allows for the accuracy of the calculus for the stresses in the loading area to be improved.

\section{Verification of the Analytical Model with the Numerical Results}

Before comparing the results of the simulations with the theoretical models, it is necessary to verify that the developed finite element models are well defined. For this, the computational results have been compared with those obtained by Erarslan et al. [11] for the contact angles of $15^{\circ}, 20^{\circ}$, and $30^{\circ}$. These include the heterogeneity of the mechanical properties of the rock in the numerical model. The authors concluded that the computational results correctly characterize the real fracture behaviour of the tested rock. Their results and our numerical results are shown in Table 2. It can be seen that, despite not considering the heterogeneity of the disk material as did Erarslan et al. [11], our simulation results do not differ significantly from the results of these authors. Therefore, it can be concluded that the heterogeneity of the material does not significantly affect the magnitude of the indirect tensile strength. According to the results of different authors $[11,24]$, it can be said that the heterogeneity of the material probably affects the speed and evolution of the disk failure once the crack begins.

For the calibration and verification of the finite element model, the simulation results have also been compared with the experimental results of the Brazilian test presented by Jin et al. [38]. The authors analyse the influence of the specimen size on the quasi-static and dynamic experimental studies on the tensile strength of concrete and mortar disks. The concrete and mortar specimens were $70 \mathrm{~mm}$ in diameter and $30 \mathrm{~mm}$ and $55 \mathrm{~mm}$ thick, respectively. The Young moduli of the cement and concrete calculated by the authors were 30.32 GPa and 27.45 GPa, respectively. The Poisson ratio for both materials was 0.18 . To reduce the stress concentration in the contact zone, they used a $20^{\circ}$ loading arc.

Table 3 shows the experimental tensile strength obtained by Jin et al. [38] with their corresponding expanded uncertainty for a confidence level of $95 \%$ and the numerical tensile stress from our simulations models.

According to Table 3, it can be concluded that the results of the computational model developed in the actual research work adequately represent the tensile strength for both cement and concrete for the different thicknesses studied by Jin et al. [38]. According to the results of these authors, one could say that the elastic properties of the material seem to 
TABLE 2: Comparative analysis of the numerical simulations with the results of Erarslan et al. [11].

\begin{tabular}{lcc}
\hline Loading arc angle $\left(^{\circ}\right)$ & Tensile stress at the centre of the disk (MPa) [11] & Tensile stress from our simulations $(\mathrm{MPa})$ \\
\hline 15 & 8.04 & 8.20 \\
20 & 8.29 & 8.45 \\
30 & 8.70 & 8.64 \\
\hline
\end{tabular}

TABLe 3: Comparative analysis of the numerical simulations with the results of Jin et al. [38] for a confidence level of $95 \%$.

\begin{tabular}{|c|c|c|c|c|c|c|}
\hline \multirow[t]{2}{*}{ Thickness (mm) } & \multicolumn{2}{|c|}{ Failure load (kN) } & \multicolumn{2}{|c|}{$\begin{array}{l}\text { Tensile strength at the centre of } \\
\text { the disk (MPa) [38] }\end{array}$} & \multicolumn{2}{|c|}{$\begin{array}{l}\text { Tensile stress from our } \\
\text { simulations }(\mathrm{MPa})\end{array}$} \\
\hline & Concrete & Mortar & Concrete & Mortar & Concrete & Mortar \\
\hline 30 & 8.71 & 11.44 & $2.64 \pm 0.14$ & $3.6 \pm 0.10$ & 2.50 & 3.36 \\
\hline 55 & 15.71 & 20.26 & $2.6 \pm 0.10$ & $3.35 \pm 0.12$ & 2.44 & 3.20 \\
\hline
\end{tabular}

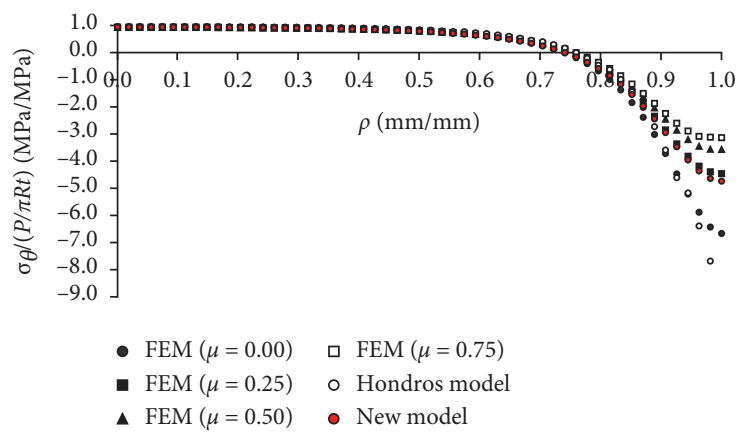

(a)
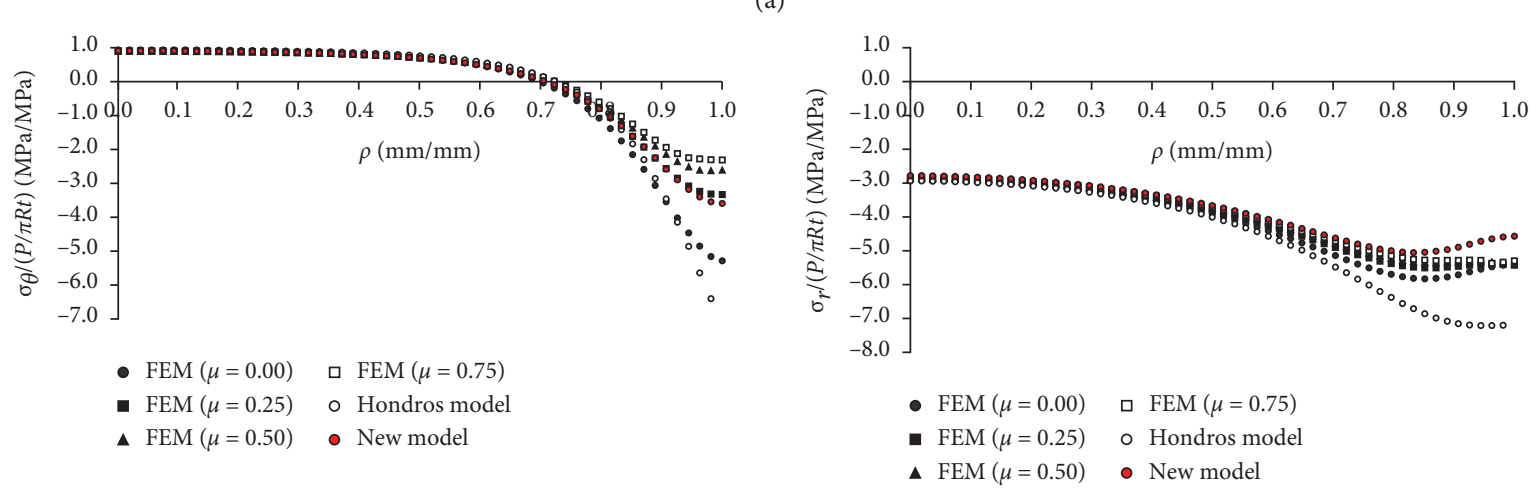

(b)
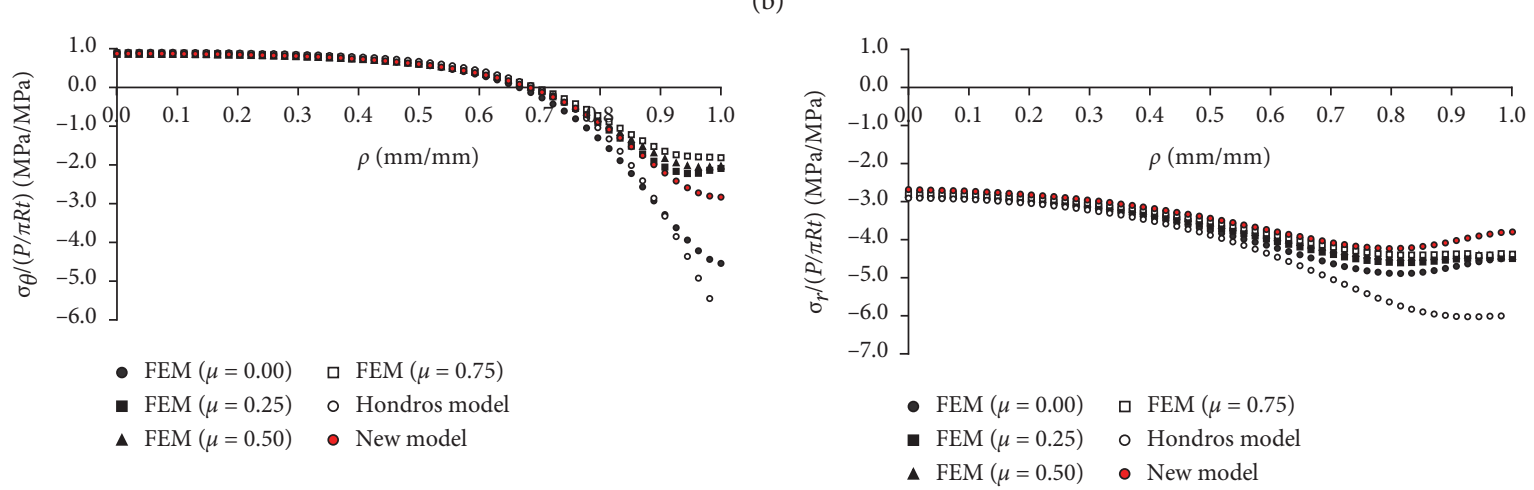

(c)

Figure 7: Dimensionless tangential and radial stresses along the vertical radii of the disk. (a) Loading arc of $20^{\circ}$. (b) Loading arc of $25^{\circ}$. (c) Loading arc of $30^{\circ}$.

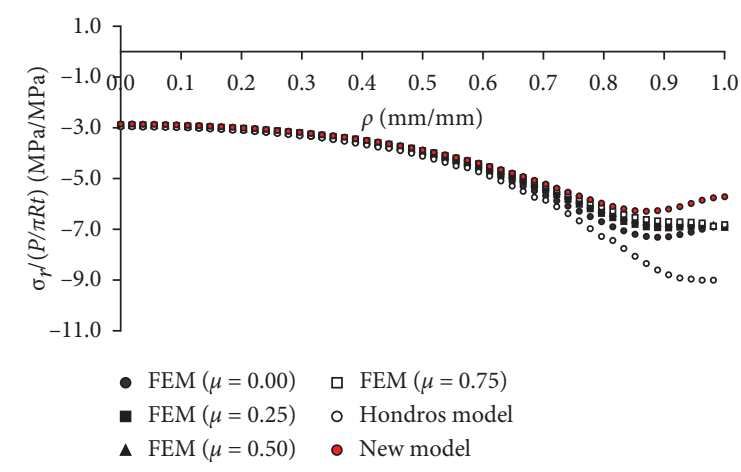




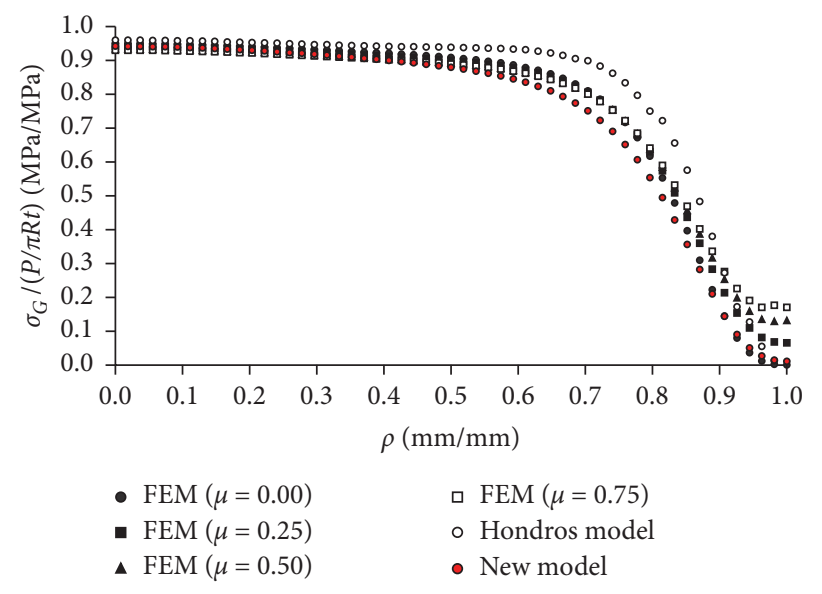

(a)

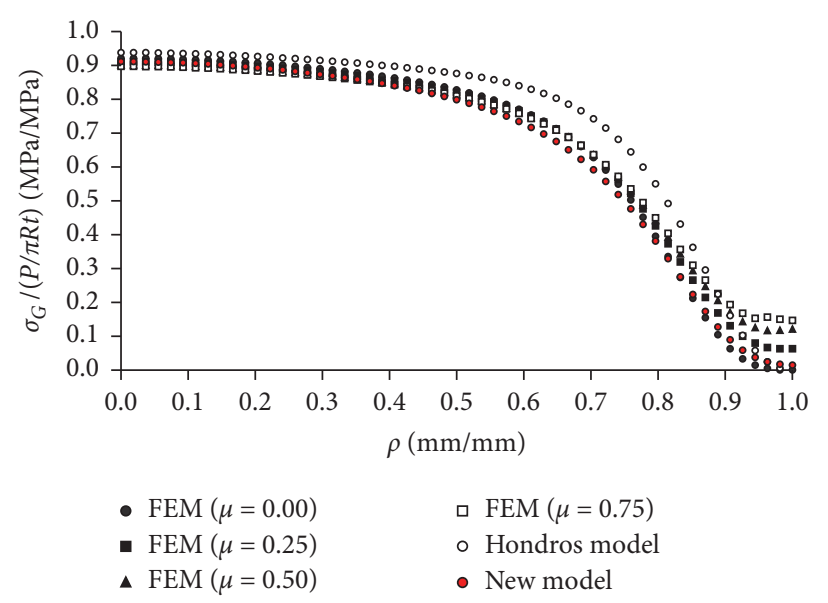

(b)

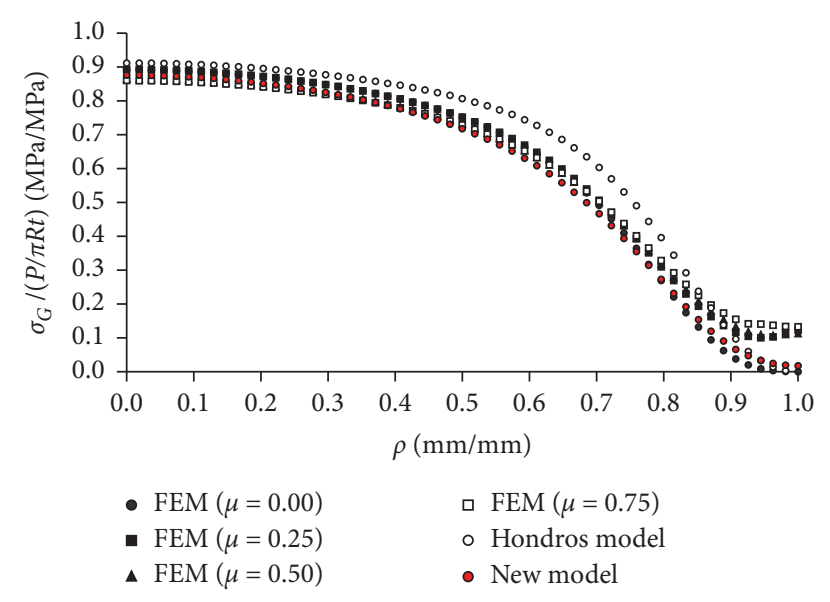

(c)

FIgURE 8: Dimensionless equivalent stress along the vertical radii of the Brazilian disk. (a) Loading arc of $20^{\circ}$. (b) Loading arc of $25^{\circ}$. (c) Loading arc of $30^{\circ}$.

affect the magnitude of the failure load, but not the accuracy of the calculated tensile stress if the experimental and numerical results are compared. It is thus clear that it is impossible to calculate the ultimate load through simulations, but it is interesting to verify how the properties of the material can affect to the tensile strength for the same load magnitude value.

Therefore, it is confirmed that the computational models can be considered appropriate for the calculus of the splitting tensile stress in the Brazilian disk with loading arcs.

Figure 7 presents the distribution of the dimensionless tangential $\sigma_{\theta} /(P / \pi R t)$ and radial stresses $\sigma_{r} /(P / \pi R t)$ along the vertical radius of the disk for loading arcs of $20^{\circ}, 25^{\circ}$, and $30^{\circ}$. The numerical solutions as well as Hondros and the proposed analytical expressions are represented.

As can be seen, there is not a significant difference in the evolution of the calculated dimensionless theoretical tangential stress, except for the points closer to the contact. The Hondros tangential stress shows a behaviour more similar to the numerical result for the frictionless contact assumption compared to the new model. However, the last is best suited for the rest of the contact surface conditions. On the contrary, the new model improves the predictions of the radial stress, especially for a contact angle of $30^{\circ}$. Therefore, it confirms that the assumed pressure distribution has a greater impact on the radial stresses than on the tangential ones.

Figure 8 shows the dimensionless Griffith equivalent stress along the vertical radius of the disk for the FEM and theoretical models. As can be observed, the new model provides better results with respect to the simulations, along with a slight underestimating tendency compared to the Hondros model, thus producing safer results. The equivalent stress calculated with the new model does not seem to be affected by the length of the contact arc compared to the ones calculated with the Hondros model.

The changes in the contact conditions seem to have no influence in areas far from the contact. However, a deeper analysis is needed in order to quantify the differences between the analytical models with respect to the numerical solutions. 


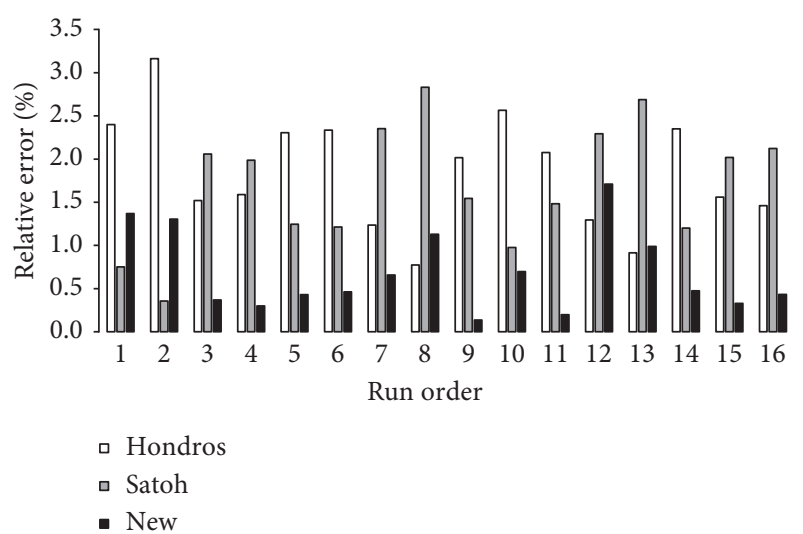

(a)

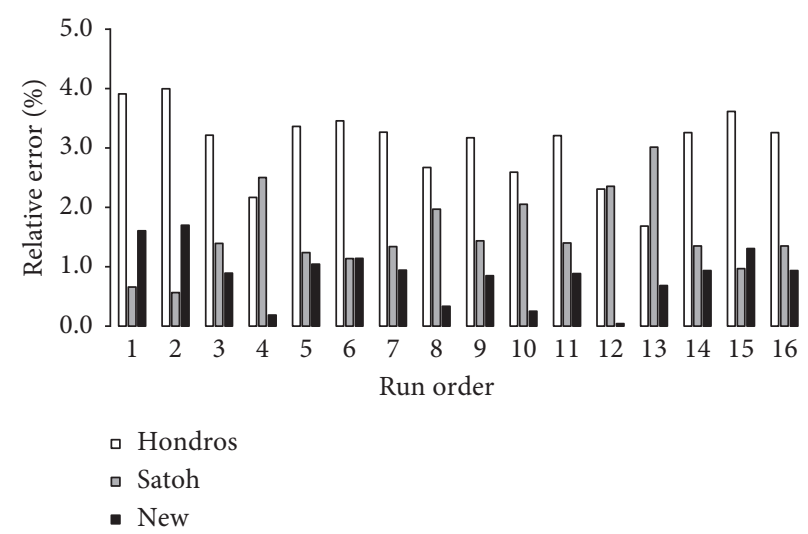

(b)

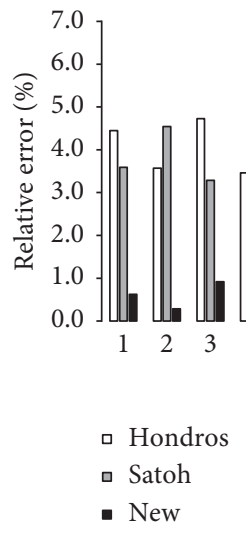

(c)

FIGURE 9: Relative error of the dimensionless equivalent stress in the centre with respect to the FEM Brazilian disk for the factorial numerical design. (a) Loading $\operatorname{arc}$ of $20^{\circ}$. (b) Loading arc of $25^{\circ}$. (c) Loading $\operatorname{arc}$ of $30^{\circ}$.

6.1. Influence of the Material Properties on the Accuracy of the Maximum Griffith Equivalent Stress. The theoretical models analysed in the actual research are based on the supposed elastic behaviour of rock and concrete. Therefore, it is necessary to verify and identify the areas of the disk that are less sensitive to elastic properties, friction, and contact angle. According to the results of the simulations developed from the computational experimental design shown in Table 1, the considered physical properties have a negligible effect in the areas near the centre of the disk. The numerical equivalent tensile stress in the centre of the disk has an experimental deviation in percentage terms with respect to the mean of $0.7 \%, 0.5 \%$, and $0.4 \%$, for contact angles of $20^{\circ}, 25^{\circ}$, and $30^{\circ}$, respectively. Therefore, it has been confirmed that the effect of the properties of the material, together with the friction present in the loading area, is negligible in the calculus of the maximum tensile strength for contact angles of $20^{\circ}$ to $30^{\circ}$.

However, the effects of Young's modulus, Poisson's ratio, and friction coefficient are significant near the contact zone. We have been able to verify that from a radius ratio $\rho \geq 0.8$, the equivalent tensile stress becomes unstable and therefore difficult to predict with the analytical models. It has been observed that as the contact angle increases, the possible variation in the equivalent stress values in the area near the contact decreases. The greatest variation of the equivalent stress in this area $(\rho=0.8)$ is the one corresponding to a contact angle of $20^{\circ}$, with approximately $17 \%$. On the contrary, for a contact angle of $30^{\circ}$, the variation decreases to $11 \%$. These results have been calculated taking the magnitude of the equivalent stress resulting from the simulation model of Run order 1 of Table 1 as a reference.

Figure 9 presents the comparative analysis of the factorial numerical design indicated in Table 1 for contact angles of $20^{\circ}, 25^{\circ}$, and $30^{\circ}$. The magnitude compared is the maximum dimensionless equivalent stress, located in the centre of the disk. Additionally, the improvement of the Hondros model, proposed by Satoh (15), has been considered in this comparison:

$$
\sigma_{G C}=\sigma_{G} \cdot \frac{\sin \alpha \cos ^{2} \alpha}{\alpha} .
$$

Figure 9 indicates that the properties of the material and the friction existing in the contact zone do not have a significant influence on the accuracy of the results according to the randomness of the relative errors. It is observed that smaller differences are obtained in all cases with the proposed model, with all being below $1.8 \%$. Moreover, the increase in the contact arc length affects the predictions of all the theoretical models analysed. However, the difference is nearly insignificant in the case of the new model. 
TABLE 4: Mean absolute percentage error of the theoretical equivalent stress.

\begin{tabular}{lccr}
\hline Loading arc angle & Hondros solution (\%) & Satoh solution (\%) & New model (\%) \\
\hline $20^{\circ}$ & 2.08 & 1.81 & 0.80 \\
$25^{\circ}$ & 3.67 & 1.87 & 1.02 \\
$30^{\circ}$ & 4.52 & 3.52 & 0.95 \\
\hline
\end{tabular}

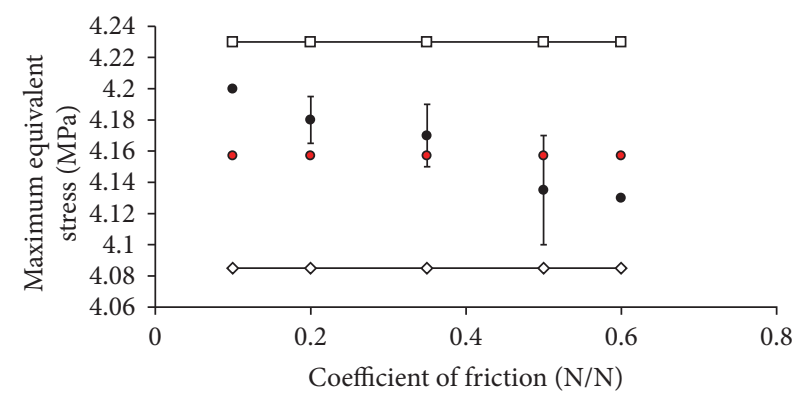

- Numerical results $\multimap$ Satoh

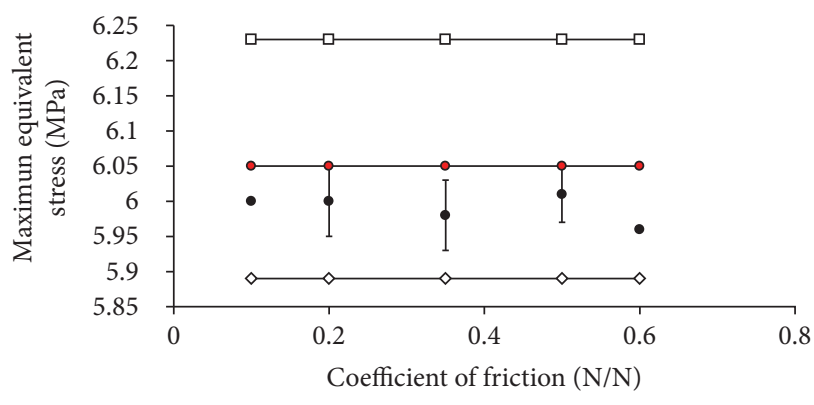

- Numerical results $\leadsto$ Satoh

$\rightarrow$ Hondros $\rightarrow$ New

(b)

(a)

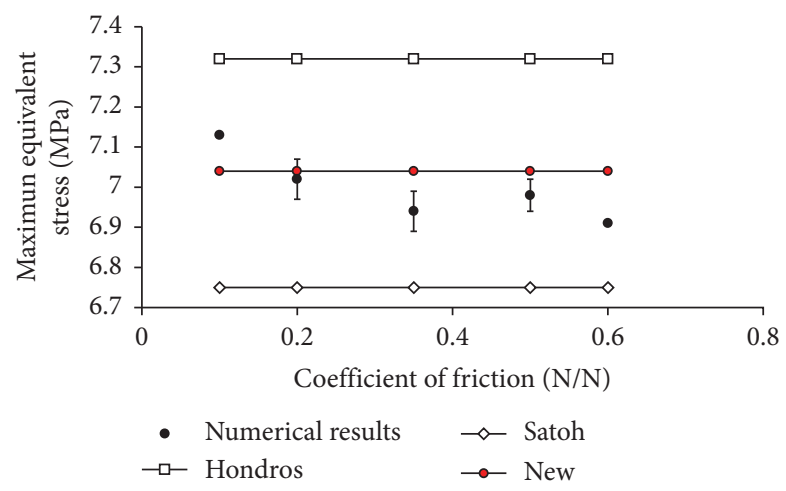

(c)

FIGURE 10: Maximum equivalent stress with respect to the coefficient of friction. (a) Loading arc of $20^{\circ}$. (b) Loading $\operatorname{arc~of~} 25^{\circ}$. (c) Loading arc of $30^{\circ}$.

Table 4 presents the mean absolute percentage of the error for the theoretical equivalent stresses with respect to the factorial design results from Figure 9. It can be noted that the correction proposed by Satoh improves the original Hondros solution. On the contrary, the errors of the new proposed model remain nearly constant and do not exceed $1.1 \%$.

Figure 10 shows the average maximum FEM stresses of the factorial design with respect to the friction coefficient. Notice that the numerical solutions are located within the limits marked by the Hondros and Satoh models.

According to Figure 10, it can be seen that the new model offers a solution that is located in the middle of the evolution of the numerical solution with the friction coefficient.

6.2. Statistical Verification of the Available Theoretical Solutions. To verify if the predictions of the available theoretical solutions are a good prediction of the numerical solutions and the real tests, it is necessary to consider the uncertainty in the models [22]. However, it has been decided to only take the uncertainties that affect the analytical solutions into account and to consider the numerical solution as deterministic because a normalized uncertainty procedure for this models has not yet been specified. Therefore, it can be said, with a confidence level of $95 \%$, that the theoretical solutions are a good representation of the numerical results, if the value of the maximum equivalent stress is within the limits of the theoretical expanded uncertainties. The sources of uncertainty are the applied load $P$, the contact angle $2 \alpha$, the radii $R$, and the thickness $t$ of the disk.

It was considered that the uncertainty of the load corresponds to the values of a universal testing machine class II [39]. The uncertainty propagation was developed by Monte Carlo methods according to the Guide for the expression of the uncertainty in measurement (GUM) [41]. Table 5 shows the values of the uncertainties considered in the analysis and the probability density function of each variable. The 
uncertainties of the geometrical parameters $(R, t$, and $2 \alpha)$ correspond to the typical uncertainties of the tools used to measure the magnitudes.

Figure 11 shows the probable values of the available theoretical solutions with respect to the finite element results for a confidence level of $95 \%$ with the contact angles of $20^{\circ}$, $25^{\circ}$, and $30^{\circ}$. It can be observed that the model proposed by Hondros is only able to predict the maximum Griffith equivalent stress of eight of the 16 materials analysed for a contact angle of $20^{\circ}$ (Figure 11(a)). From the uncertainty point of view, the Hondros model is not suitable for a contact angle higher than $20^{\circ}$ since it was observed that the numerical results are outside the confidence level. On the contrary, the Satoh correction improves the predictions based on the Hondros solution for a contact angle of $25^{\circ}$ (Figure 11(b)). However, while the Satoh factor is based on a correction between experimental and theoretical results, it lacks any justification that explains the analysed physical phenomenon.

The uncertainty quantification allows for the quality of the predictions made with the new model to be confirmed. The possible values of the proposed analytical model coincide with most of the results obtained from the simulations. It can be seen that, for a contact angle of $20^{\circ}$, only one result of the FEM models is outside the confidence limits (Figure 11(a)), while in the rest of the studied contact angles, only two numerical results fall outside the range of the global uncertainty for a confidence level of 95\% (Figures 11(b) and 11(c)). Therefore, it can be confirmed that the differences between the Hondros model with respect to the results of the new model and the simulations are due to the different boundary conditions that have been assumed and specifically to the distribution of the load on the contact zone.

\section{Statistical Validation of the Tensile Strength with the Results of Other Authors}

Erarslan et al. [11] recommended considering some intrinsic material properties, such as fracture toughness, crack location, and propagation, in order to find the optimum condition allowing for the determination of the magnitude of the indirect tensile strength with the higher possible accuracy. They suggested using the empirical expression (16) between the mode I fracture toughness and the tensile strength of rock [41] to verify the optimum loading arc length:

$$
K_{I C}=0.27+0.107 \sigma_{t}
$$

where $K_{I C}$ is the mode I fracture toughness and $\sigma_{t}$ is the tensile strength of the rock.

This recommendation is used to verify the new model. The sample of these authors was a Brisbane tuff Brazilian disk with a diameter of $52 \mathrm{~mm}$ and a thickness of $26 \mathrm{~mm}$. They obtained a tensile experimental strength with (16) knowing that the fracture toughness of this type of rock is $K_{I C}=0.18 \mathrm{MPa} \mathrm{m}^{1 / 2}$. A comparative statistical analysis is shown in Table 6 . The loads used to calculate the theoretical tensile strength were $19.2 \mathrm{kN}$ and $21.1 \mathrm{kN}$ for $20^{\circ}$ and $30^{\circ}$ contact angles, respectively [11]. The uncertainty of the parameters is the same as in Table 3. The uncertainty quantification was developed according to the numerical procedure given by GUM [40].

The results presented in Table 6 indicate that the three theoretical solutions are close to the experimental tensile strength for this type of rock. However, better results are obtained with the new model for a contact angle of $20^{\circ}$. The magnitudes given by the Hondros and Satoh models, respectively, show an over and underestimating tendency with respect to the experimental result, as seen in Figures 10 and 11 .

The normalized error ( $E_{N}$ number) (17) can be used as a comparison tool between the theoretical model results (Theo) and the experimental ones (Exp), when the uncertainty of both is considered. The normalized error compares the error with the combined expanded uncertainty, and if the score is less than one, it can be said that both results are compatible [42]:

$$
\begin{aligned}
E_{N} & =\frac{\mid \text { Error } \mid}{\sqrt{U(\text { Error })}}=\frac{\mid \text { Exp }- \text { Theo } \mid}{\sqrt{U^{2}(\operatorname{Exp})-U^{2}(\text { Theo })}} \\
& =\frac{\mid \text { Exp }- \text { Theo } \mid}{\sqrt{\left(\left(\text { Exp }_{\text {high }}-\text { Exp }_{\text {low }}\right) / 2\right)^{2}-\left(\left(\text { Theo }_{\text {high }}-\text { Theo }_{\text {low }}\right) / 2\right)^{2}}},
\end{aligned}
$$

where for the case analysed in this research work,

(i) Exp is the indirect tensile strength

(ii) Exphigh and Exp Exw $_{\text {low }}$ are, respectively, the lower and upper limits of the probable values of the experimental results for a coverage level of $95 \%$

(iii) Theo $=$ theoretical tensile stress

(iv) Theo ${ }_{\text {high }}$ and Theo low $_{\text {are, respectively, the lower and }}$ upper limits of the probable values of the theoretical solutions for a coverage level of $95 \%$

If the above equation (17) is applied to the comparative results shown in Table 6 , assuming that the uncertainty of the experimental result is zero $\left(\operatorname{Exp}_{\text {high }}=\operatorname{Exp}_{\text {low }}=0\right)$ because we do not know its value, the level of accuracy of the models studied can be tested. The normalized errors for the three models are 0.86 and 3.29 for the Hondros model, 1.21 and 1.33 for the Satoh solution, and 0.23 and 1.08 for the new model. According to the values of the standardized errors, the solutions of the new model have the best accuracy in the range of the analysed contact angles. In fact, a small disturbance of the applied load (approximately 1\%) would cause the experimental value to be within the limits of the possible theoretical values of the new model for a contact angle of $30^{\circ}$.

$\mathrm{Yu}$ et al. [16] conducted several Brazilian tests with the loading arc of $20^{\circ}$ using the simplified expression of the indirect tensile strength suggested by the ISRM [1]. Table 7 shows their results.

To verify if the solution of the ISRM and the expressions analysed in the present research work are a good representation of the Brazilian test with loading arcs, 
TABLE 5: Uncertainties of the theoretical variables.

\begin{tabular}{lccc}
\hline Variable & Units & Uncertainty $u$ & Probability density function \\
\hline$P$ & $\mathrm{~N}$ & $8.75 \times 10^{-3} \mathrm{P}$ & Normal \\
$D$ & $\mathrm{~mm}$ & $2.89 \times 10^{-2}$ & Normal \\
$t$ & $\mathrm{~mm}$ & $2.89 \times 10^{-2}$ & Normal \\
$2 \alpha$ & Radians & $1.00 \times 10^{-3}$ & Rectangular \\
\hline
\end{tabular}

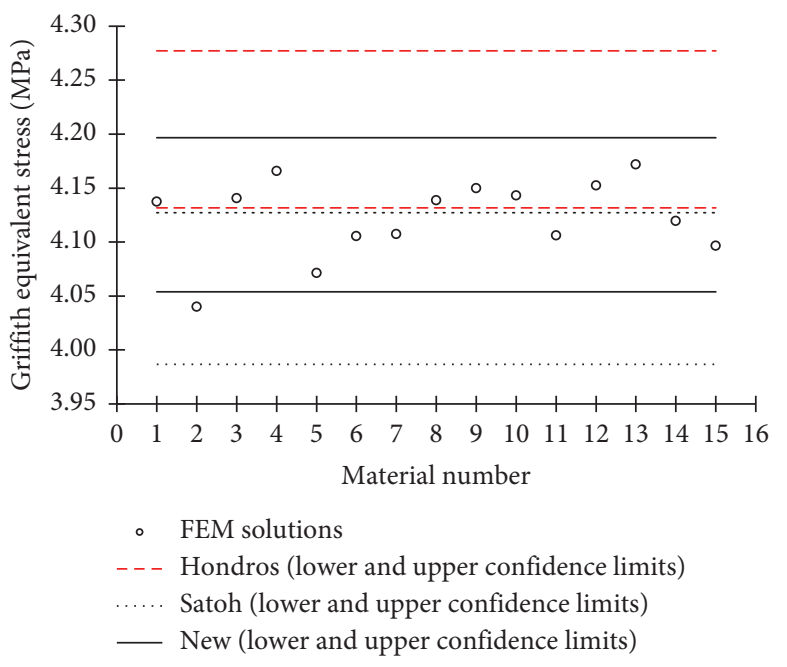

(a)

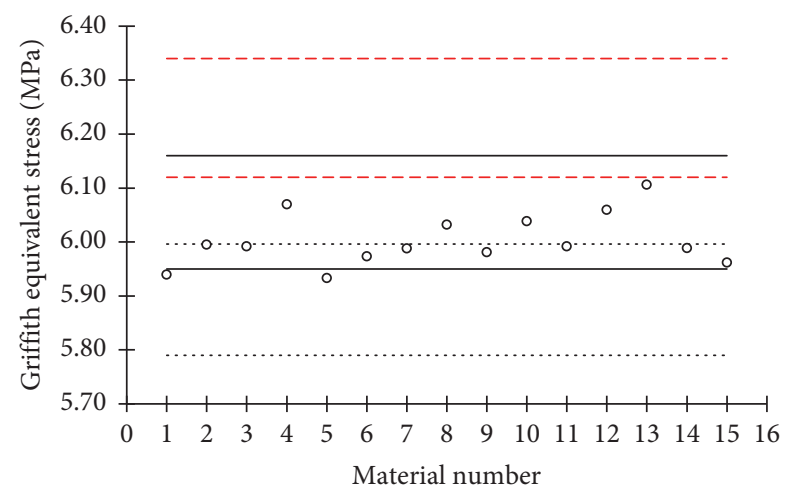

- FEM solutions

- - - Hondros (lower and upper confidence limits)

..... Satoh (lower and upper confidence limits)

_ New (lower and upper confidence limits)

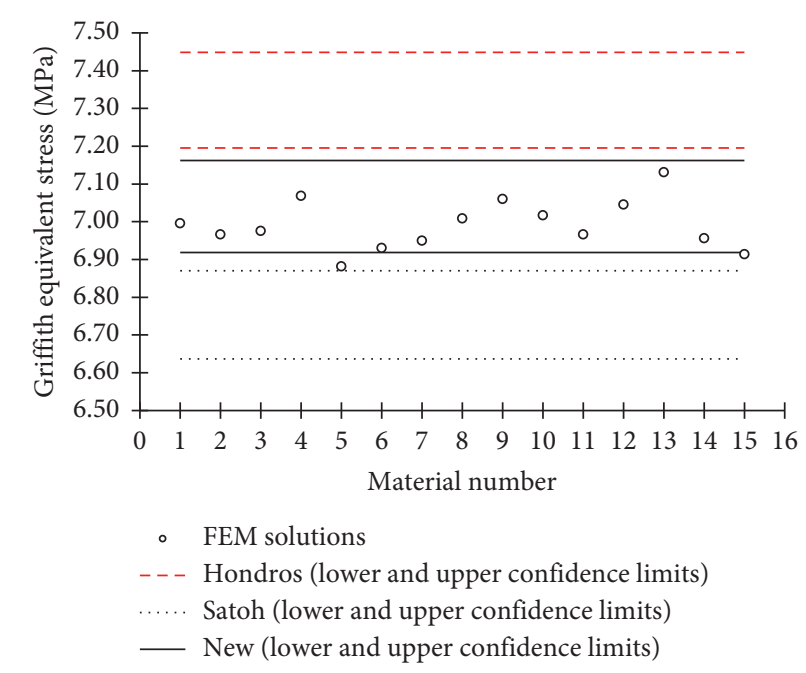

(b)

(c)

Figure 11: Comparison of the numerical results and the probable theoretical solutions for a confidence level of $95 \%$. (a) Loading arc of $20^{\circ}$. (b) Loading arc of $25^{\circ}$. (c) Loading arc of $30^{\circ}$.

additional simulations have been conducted with the experimental values of Table 7 . As in the study of Yu et al. [16], Young's modulus used was $20 \mathrm{GPa}$ and Poisson's ratio was 0.2 .

Table 8 presents a statistical comparison of the final numerical indirect tensile strength of the cement mortar tested by Yu et al. [16] with the theoretical models. Because the sample size of the cement mortar experimented on could be considered insufficient for statistical inference, the upper and lower limits of the numerical results were determined by
10000 reiterations using a resampling technique known as the bootstrap method [43] with all the available FEM solutions. Considering that numerous investigations have certified that the solution provided by the finite elements methods accurately represent this type of indirect test $[11,24]$, the result of the simulations conducted will be taken as a reference value.

In Table 8 , it can be seen that all the analytical models considered have some value in common with the possible numerical tensile strengths, according to the lower and 
TABLE 6: Comparative analysis of the theoretical tensile strength with the results of other authors.

\begin{tabular}{|c|c|c|c|c|c|}
\hline \multirow{2}{*}{ Loading arc angle $\left({ }^{\circ}\right)$} & \multirow{2}{*}{$\begin{array}{l}\text { Indirect tensile } \\
\text { strength of Brisbane } \\
\text { tuff }(\mathrm{MPa})[11]\end{array}$} & \multirow[b]{2}{*}{ Numerical tensile strength $(\mathrm{MPa})[11]$} & \multicolumn{3}{|c|}{ Theoretical solutions $(\mathrm{MPa})$} \\
\hline & & & Hondros & Satoh & New model \\
\hline 20 & 8.55 & 8.29 & $8.68(8.53,8.83)$ & $8.37(8.23,8.52)$ & $8.52(8.37$ \\
\hline 30 & & 8.70 & $9.06(8.90,9.21)$ & $8.36(8.21,8.50)$ & $8.71(8.56,8.86)$ \\
\hline
\end{tabular}

TABLE 7: Experimental results from other research work [16].

\begin{tabular}{lccc}
\hline Cement mortar number & Diameter $(\mathrm{mm})$ & Thickness $(\mathrm{mm})$ & Experimental load $(\mathrm{N})$ \\
\hline 1 & 49.36 & 9.98 & 3756 \\
2 & 49.40 & 10.18 & 3596 \\
3 & 49.42 & 10.10 & 2640 \\
4 & 49.66 & 10.26 & 3918 \\
5 & 49.20 & 10.22 & 3660 \\
6 & 49.42 & 10.36 & 4096 \\
7 & 49.40 & 9.76 & 3630 \\
8 & 49.38 & 9.88 & 3556 \\
9 & 49.44 & 10.10 & 3966 \\
10 & 49.40 & 10.20 & 3598 \\
11 & 49.44 & 10.10 & 4528 \\
12 & 49.36 & 9.94 & 3966 \\
13 & 48.48 & 10.14 & 3194 \\
14 & 49.32 & 10.04 & 3458 \\
\hline
\end{tabular}

TABLE 8: Statistical comparison of the final numerical indirect tensile strength of the cement mortar tested by Yu et al. [16] with the theoretical models.

\begin{tabular}{|c|c|c|c|c|}
\hline \multirow{2}{*}{ Numerical tensile strength of mortar cement $\sigma_{G_{-} \mathrm{FEM}}(\mathrm{MPa})$} & \multicolumn{4}{|c|}{ Theoretical solutions $\sigma_{G_{-} \text {Theo }}(\mathrm{MPa})$} \\
\hline & ISRM & Hondros & Satoh & New model \\
\hline $4.36[4.08,4.64]$ & $4.70[4.61,4.79]$ & $4.52[4.43,4.60]$ & $4.36[4.28,4.44]$ & $4.43[4.35,4.51]$ \\
\hline
\end{tabular}

upper limits for a confidence level of $95 \%$. However, for the statistical validation of the analytical models, it is required that the difference between the mean values of the reference solution and the other solutions must be smaller than the combined expanded uncertainty of both. We can define a total uncertainty (18) equal to the sum of the variance of the FEM results $u^{2}\left(\sigma_{G_{-} \text {FEM }}\right)$ and the theoretical results $u^{2}\left(\sigma_{G_{-} \text {Theo }}\right)$, as it was verified that these are normally distributed random variables:

$$
u_{\text {Total }}=\sqrt{u^{2}\left(\sigma_{G_{-} \text {FEM }}\right)+u^{2}\left(\sigma_{G_{-} \text {Theo }}\right)} .
$$

This total uncertainty will be associated with the theoretical results as recommended by Hills [21]. Therefore, we can conclude that the theoretical tensile strength is valid if the mean numerical tensile strength $\sigma_{G_{-} \text {FEM }}$ falls inside its coverage limits of $95 \%$ [21].

Figure 12 shows the histogram distribution of the theoretical tensile strength calculated by $10^{6}$ Monte Carlo reiterations, as well as the upper and lower limits of the total uncertainty for a confidence level of $95 \%$.

In Figure 12, it can be observed that the ISRM solution falls outside of the coverage limits of $95 \%$, so this is the only solution that cannot be declared valid, i.e., this solution does not represent the FEM results. The best result in this case is obtained with the Satoh correction followed by the new model prediction and the Hondros model. It can be said that the configuration of $20^{\circ}$ represents the optimal boundary condition because all the solutions, except the ISRM which does not consider this angle, fit with the finite element solution. For this contact length, the Saint-Venant principle [44] is fulfilled because the effects of the loading distribution with the same magnitude dissipate quickly as the distance increases such that they can be considered insignificant.

Considering that the properties of the material do not significantly affect the results of the splitting tensile stress in the centre of the disk for the same load magnitude, it was decided to analyse the stress in a steel disk submitted to a longitudinal compression with loading arcs. The reason for using steel instead of materials such as rock or concrete is that strain gages can be easily instrumented to calculate the tensile stress in the centre of the disk. The appropriate gage length for materials such as concrete depends on the size of the grain. In this case, it is recommended to use a measuring grid length five times longer than the largest aggregate grain size [45]. On the contrary, with the steel being a homogeneous material, the strain gages of a shorter length than rock and concrete can be used. Therefore, the difference between the average stress measured by the strain gages and the stress in the centre of the disk can be considered negligible. 


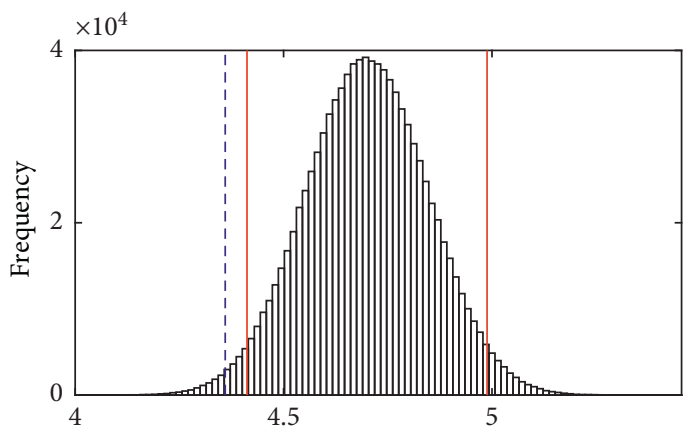

(a)

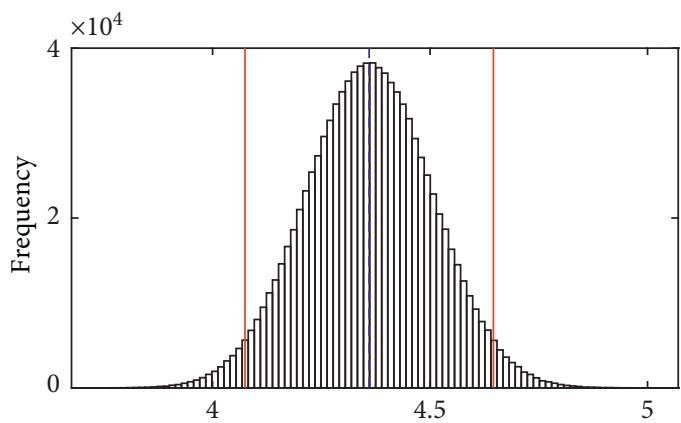

(c)

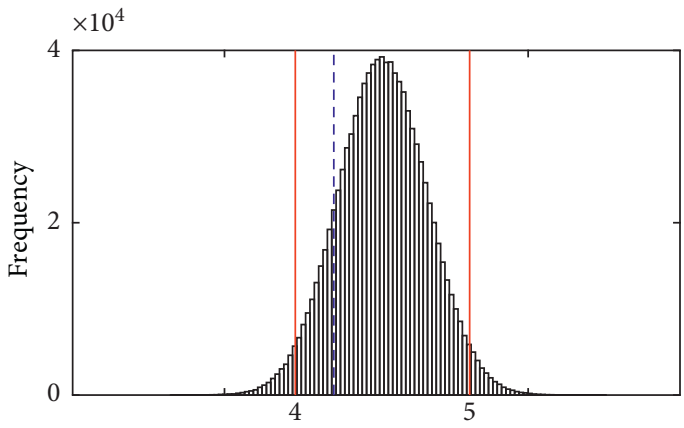

(b)

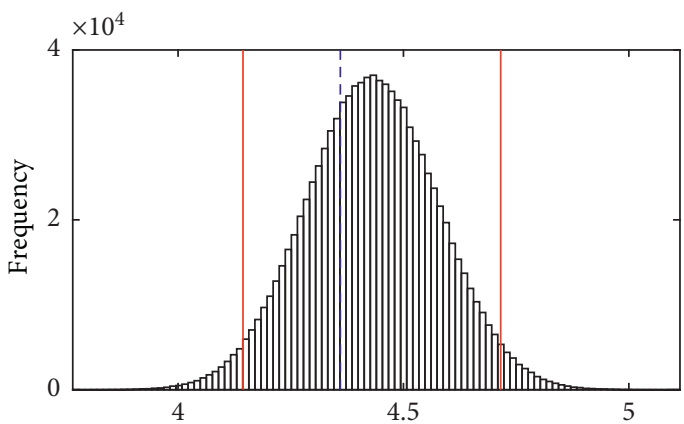

(d)

FIGURE 12: Comparison of the numerical results, represented by a dashed line, and the probable theoretical solutions of the tensile strength for a confidence level of 95\%. (a) ISRM tensile strength. (b) Hondros tensile strength. (c) Satoh tensile strength. (d) New model tensile strength.

An F114 steel disk with a $151 \mathrm{~mm}$ diameter and a $76.3 \mathrm{~mm}$ thickness was instrumented with three $6 \mathrm{~mm}$ grid length stacked rectangular rosettes aligned with the transverse and radial directions in three different positions. Rosette 1 is in the centre of the disk, rosette 3 is near the contact zone, and rosette 2 is at an intermediate point between the centre and the contact. Figure 13 shows the experimental setup.

The compressive strengths were tested with a universal testing machine class I. The test was conducted according to the ISRM standard [1]. The disk was compressed with a loading arc of $30^{\circ}$ with steel F-131. The data acquisition system was able to simultaneously record the measured strain, the applied load, and the vertical displacement of the loading device. The transverse and radial stresses were calculated using the biaxial form of Hooke's law [46]. The Young modulus and the Poisson ratio of the steel disk are $211 \mathrm{GPa} \pm 1 \%$ and $0.3 \pm 0.5 \%$, respectively. The elastic properties were calculated from flat specimens of the same material tested following the recommendation given in $[47,48]$.

Figure 14 presents the experimental results together with the theoretical solutions. Satoh's correction factor can only be applied for the maximum stress at the centre of the disk, which is why it has not been included in the rest of the areas studied and in the radial stress comparison. The positions of the rosettes are expressed with respect to the radius of the disk; therefore, a value of 0 refers to the strain gage rosette located in the centre and that of 0.9 to the rosette bonded in the contact zone.

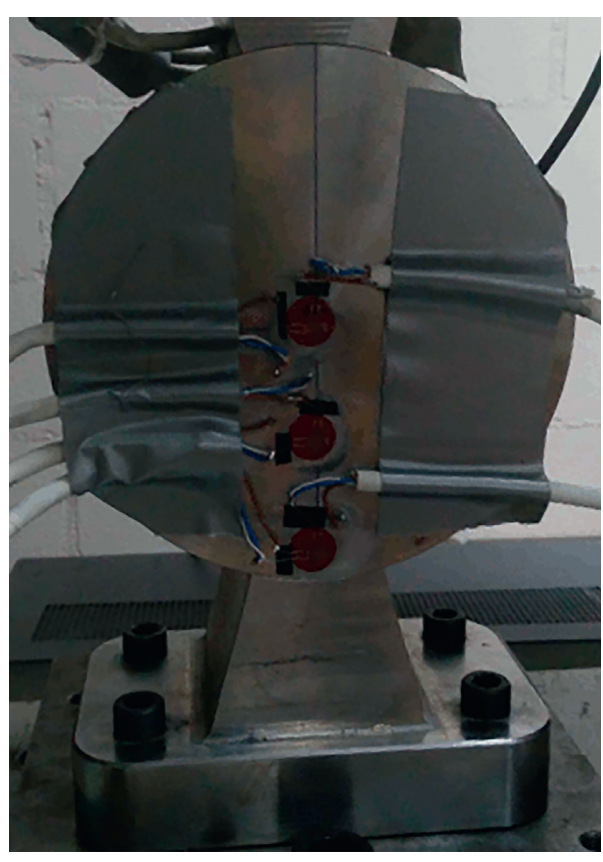

FIGURE 13: Tested setup of the steel specimen under a $30^{\circ}$ loading arc.

According to Figure 14, the available solutions are close to the experimental results except in the contact zone. Therefore, it can be affirmed that the theoretical solutions resemble the real model as we move away from the contact 


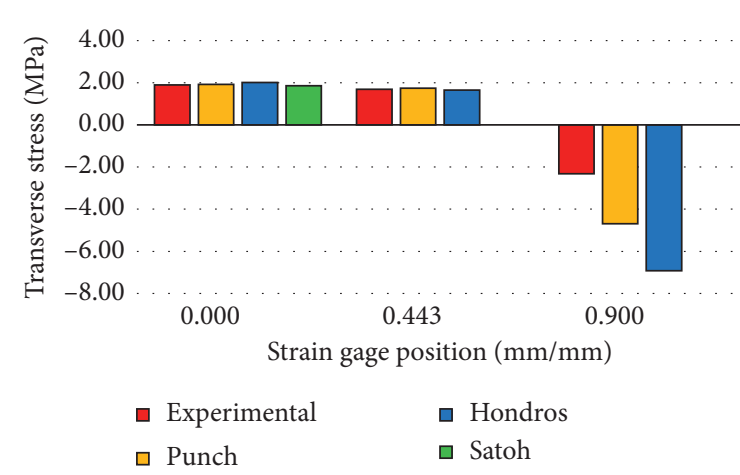

(a)

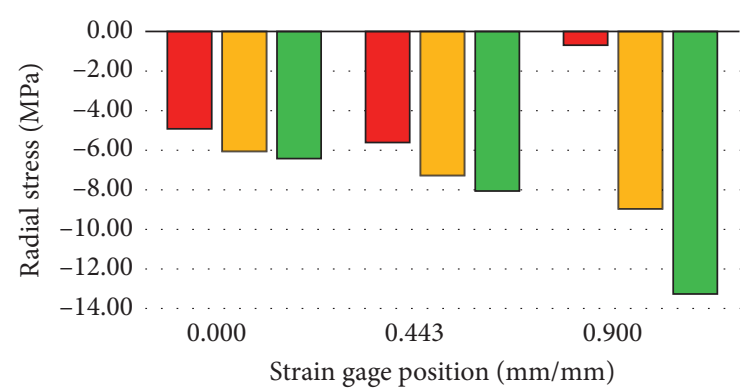

- Experimental

$\square$ Punch

口 Hondros

(b)

FIgURE 14: Comparison results in terms of (a) the transverse stress and (b) the radial stress.

TABLE 9: Statistical comparison of the experimental transverse stress in the centre the steel disk with the theoretical models.

\begin{tabular}{lcccccc}
\hline \multirow{2}{*}{ Experimental transverse stress $\sigma_{\text {EXP }}(\mathrm{MPa})$} & \multicolumn{2}{c}{ Theoretical solutions $\sigma_{G_{-} \text {Theo }}(\mathrm{MPa})$} & \multicolumn{2}{c}{$E_{N}(\mathrm{MPa} / \mathrm{MPa})(17)$} \\
& Hondros & Satoh & New model & Hondros & Satoh & New model \\
\hline $1.90[1.88,1.92]$ & $1.99[1.96,2.03]$ & $1.84[1.80,1.87]$ & $1.92[1.88,1.95]$ & 2.01 & 1.66 & 0.55 \\
\hline
\end{tabular}

area as described in the Saint-Venant principle [44]. The best behaviour is observed for the transverse stress at the centre of the disk and in the studied intermediate position (Figure 14(a)). Additionally, it is observed that the prediction of the new model is closer to the experimental stress than the other solution for the three strain gage rosettes.

The differences in the transverse stress in the centre of the disk are $0.23 \%, 4.49 \%$, and $3.62 \%$ for the new model, Hondros's model, and the Satoh correction, respectively. On the contrary, the differences in the radial stress were $23 \%$ and $31 \%$ for the new model and the Hondros model, respectively. However, we have verified that the effect of the difference between the radial stresses calculated by the models and the experimental one does not affect the value of the Griffith equivalent stress (11) in the centre of the disk.

Table 9 shows the statistical comparison of the experimental tensile stress results of the steel disk and the theoretical solutions. The uncertainty quantification of the experimental stress was developed according to GUM [49]. The experimental uncertainty considers the contribution of the experimental standard deviation of five repetitions of the Brazilian test, as well as the uncertainty of the material properties of the disk. The uncertainty in the strain gage measurements was not considered, as it was previously verified that it could be neglected.

According to the results shown in Table 9, the best score in terms of the normalized error $E_{N}$ is obtained by the new model, so it can be said that this solution and the experimental results represent the same measurand.

\section{Conclusions}

This research presented a new analytical solution for the Brazilian test with loading arcs. The validation of the proposed model is based on the comparative analysis of other analytical expressions, numerical simulations, and experimental results. For the comparison analysis, several finite element simulations were generated in order to check the sensibility of the results with the boundary conditions. The results obtained in this research study provide the following conclusions:

(i) The study of the possible influencing factors, such as the material properties, contact angle, and contact friction of the disk, performed with a factorial design of 48 numerical virtual tests indicates that the maximum equivalent stress according to the Griffith criterion is located in the centre of the disk. However, in certain cases, high equivalent stresses can be observed at the edge of the loading arcs.

(ii) For the $20^{\circ}$ loading arc configuration, it was observed that the stresses along the vertical diameter of the disk are very similar. Therefore, an immediate appearance of a central crack in the entire vertical diameter of the disk can be expected when this configuration is used. On the contrary, for a loading $\operatorname{arc}$ of $30^{\circ}$, stresses with similar values are located in a smaller area, so it can be concluded that the appearance of the crack can be better defined than the $20^{\circ}$ configuration.

(iii) According to the numerical results, the friction in the contact surface has almost no effect on the 
equivalent stress in the centre of the disk, whereas its influence increases towards the contact edge of the loading arc. Therefore, special attention should be paid to the surface finish both the disk and the loading arcs since it has been observed that an increased friction value increases the stress concentration at the edges of the contact, which can favour the appearance of unwanted cracks in this zone together with a central crack.

(iv) As for the variability of the numerical results in the centre of the disk, the experimental deviations for a confidence level of $95 \%$ are inferior to $1 \%$. It can thus be concluded that for the range analysed, all the contact angles produce a very low variability, so it can be expected that the real experimental stresses will have a small dispersion.

(v) The study of the contact pressure distribution by means of the FEM models reveals that this pressure is close to a rigid punch distribution. This allowed for a new analytical model integrating this distribution with the classical elasticity theories to be developed. The new model allows the tensile strength to be calculated correctly according to the developed statistical validation and is less sensitive to the influence of the length of the contact than the other considered models.

(vi) It has been found that the $20^{\circ}$ loading arc configuration is the least sensitive to the load distribution since all the possible solutions, for a confidence level of $95 \%$, are similar.

To summarize, 52 comparisons of the maximum tensile stress in the centre of the disk were made, which included both the numerical and experimental results of the new model presented and the models of other authors. It can be concluded that the new model guarantees a greater success in the calculus of the indirect tensile stress than the other analytical solutions. In $88 \%$ of the analysed cases, it can be confirmed that the theoretical model represents the reference tensile stress value for a confidence level of $95 \%$. However, this only happens in $21 \%$ and $33 \%$ of cases for the Hondros model and Satoh correction, respectively.

\section{Data Availability}

The data used to support the findings of this study are included within the article.

\section{Conflicts of Interest}

The authors declare that they have no conflicts of interest.

\section{Acknowledgments}

The authors of this paper acknowledge the financial support of the PhD fellowship of the Severo Ochoa Program of the Government of the Principality of Asturias (PA-14-PFBP14-067).

\section{References}

[1] ISRM, "Suggested methods for determining tensile strength of rock materials," International Journal of Rock Mechanics and Mining Sciences, vol. 15, no. 3, pp. 99-103, 1978.

[2] ASTM D3967-16, Standard Test Method for Splitting Tensile Strength of Intact Rock Core Specimens, American Society for Testing and Materials, West Conshohocken, PA, USA, 2016.

[3] ASTM C496/C496M, Standard Test Method for Splitting Tensile Strength of Cylindrical Concrete Specimens, American Society for Testing and Materials, West Conshohocken, PA, USA, 2011.

[4] S. Y. Wang, S. W. Sloan, and C. A. Tang, "Three-dimensional numerical investigations of the failure mechanism of a rock disc with a central or eccentric hole," Rock Mechanics and Rock Engineering, vol. 47, no. 6, pp. 2117-2137, 2013.

[5] Y. Yu, J. Yin, and Z. Zhong, "Shape effects in the Brazilian tensile strength test and a 3D FEM correction," International Journal of Rock Mechanics and Mining Sciences, vol. 43, no. 4, pp. 623-627, 2006.

[6] B. R. Indriyantho and Nuroji, "Finite element modeling of concrete fracture in tension with the Brazilian splitting test on the case of plane-stress and plane-strain," Procedia Engineering, vol. 95, pp. 252-259, 2014.

[7] D. J. Guerrero-Miguel, M. I. Álvarez-Fernández, C. C. GarcíaFernández, C. González-Nicieza, and C. MenéndezFernández, "Analytical and numerical stress field solutions in the Brazilian Test subjected to radial load distributions and their stress effects at the centre of the disk," Journal of Engineering Mathematics, vol. 116, no. 1, pp. 29-48, 2019.

[8] A. A. Griffith, "The phenomena of rupture and flow in solids," Philosophical Transactions of the Royal Society of London. Series A, Containing Papers of a Mathematical or Physical Character, vol. 221, no. 582-593, pp. 163-198, 1921.

[9] D. Li and L. N. Y. Wong, "The brazilian disc test for rock mechanics applications: review and new insights," Rock Mechanics and Rock Engineering, vol. 46, no. 2, pp. 269-287, 2013.

[10] C. Fairhurst, "On the validity of the "Brazilian" test for brittle materials," International Journal of Rock Mechanics and Mining Sciences \& Geomechanics Abstracts, vol. 1, no. 4, pp. 535-546, 1964.

[11] N. Erarslan, Z. Z. Liang, and D. J. Williams, "Experimental and numerical studies on determination of indirect tensile strength of rocks," Rock Mechanics and Rock Engineering, vol. 45, pp. 739-751, 2012.

[12] E. Komurlu and A. Kesimal, "Evaluation of indirect tensile strength of rocks using different types of jaws," Rock Mechanics and Rock Engineering, vol. 48, no. 4, pp. 1723-1730, 2015.

[13] Q. Z. Wang, X. M. Jia, S. Q. Kou, Z. X. Zhang, and P.-A. Lindqvist, "The flattened Brazilian disc specimen used for testing elastic modulus, tensile strength and fracture toughness of brittle rocks: analytical and numerical results," International Journal of Rock Mechanics and Mining Sciences, vol. 41, no. 2, pp. 245-253, 2004.

[14] J. C. Jaeger and E. R. Hoskins, "Rock failure under the confined Brazilian test," Journal of Geophysical Research, vol. 71, no. 10, pp. 2651-2659, 1966.

[15] M. Mellor and I. Hawkes, "Measurement of tensile strength by diametral compression of discs and annuli," Engineering Geology, vol. 5, no. 3, pp. 173-22, 1971. 
[16] Y. Yu, J. Zhang, and J. Zhang, "A modified Brazilian disk tension test," International Journal of Rock Mechanics and Mining Sciences, vol. 46, no. 2, pp. 421-425, 2009.

[17] G. Hondros, “The evaluation of Poisson's ratio and modulus of materials of a low tensile resistance by the Brazilian (indirect tensile) test with particular reference to concrete," Journal of Applied Sciences, vol. 10, pp. 243-268, 1959.

[18] S. K. Kourkoulis, C. F. Markides, and P. E. Chatzistergos, "The standardized Brazilian disc test as a contact problem," International Journal of Rock Mechanics and Mining Sciences, vol. 57, pp. 132-141, 2013.

[19] M. Serati, H. Alehossein, and D. J. Williams, "3D elastic solutions for laterally loaded discs: generalised Brazilian and point load tests," Rock Mechanics and Rock Engineering, vol. 47, no. 4, pp. 1087-1101, 2014.

[20] R. Gutiérrez-Moizant, M. Ramírez-Berasategui, S. SantosCuadros, and C. García-Fernández, "Computational verification of the optimum boundary condition of the Brazilian tensile test," Rock Mechanics and Rock Engineering, vol. 51, no. 11, pp. 3505-3519, 2018.

[21] R. Hills and T. Trucano, "Statistical validation of engineering and scientific models Background," SAND99-1256, pp. 1-84, Sandia National Laboratories, Albuquerque, NM, USA, 1999.

[22] W. Chen, L. Baghdasaryan, T. Buranathiti, and J. Cao, "Model validation via uncertainty propagation and data transformations," AIAA Journal, vol. 42, no. 7, pp. 1406-1415, 2004.

[23] C. a. Tang and S. Tang, "Applications of rock failure process analysis (RFPA) method," Journal of Rock Mechanics and Geotechnical Engineering, vol. 3, no. 4, pp. 352-372, 2011.

[24] E. Komurlu, A. Kesimal, and S. Demir, "Experimental and numerical study on determination of indirect (splitting) tensile strength of rocks under various load apparatus," $\mathrm{Ca}$ nadian Geotechnical Journal, vol. 53, no. 2, pp. 360-372, 2016.

[25] C. F. Markides, D. N. Pazis, and S. K. Kourkoulis, "Influence of friction on the stress field of the brazilian tensile test," Rock Mechanics and Rock Engineering, vol. 44, no. 1, pp. 113-119, 2011.

[26] C. C. Garcia-Fernandez, C. Gonzalez-Nicieza, M. I. AlvarezFernandez, and R. A. Gutierrez-Moizant, "Analytical and experimental study of failure onset during a Brazilian test," International Journal of Rock Mechanics and Mining Sciences, vol. 103, pp. 254-265, 2018.

[27] S. Timoshenko, Theory of Elasticity, McGraw-Hill, New York, NY, USA, 1951.

[28] K. L. Johnson, Contact Mechanics, Cambridge University Press, Cambridge, UK, 1985.

[29] D. S. Simulia, Abaqus Documentation, 2016.

[30] Y. Jianhong, F. Q. Wu, and J. Z. Sun, "Estimation of the tensile elastic modulus using Brazilian disc by applying diametrically opposed concentrated loads," International Journal of Rock Mechanics and Mining Sciences, vol. 46, no. 3, pp. 568-576, 2009.

[31] M. I. Álvarez Fernández, C. González Nicieza, M. B. Prendes Gero, J. R. García-Menéndez, J. C. Peñas Espinosa, and F. J. Suarez Dominguez, "Numerical analysis of the influence of sample stiffness and plate shape in the Brazilian test," Dyna, vol. 82, no. 194, pp. 79-85, 2015.

[32] N. J. S. Gorst, S. J. Williamson, P. F. Pallett, and L. A. Clark, Friction in Temporary Works, Health and Safety Executive, London, UK, 2003.

[33] T. Ayub, N. Shafiq, and M. F. Nuruddin, "Mechanical properties of high-performance concrete reinforced with basalt fibers," Procedia Engineering, vol. 77, pp. 131-139, 2014.
[34] E. Herve, S. Care, and J. P. Seguin, "Influence of the porosity gradient in cement paste matrix on the mechanical behavior of mortar," Cement and Concrete Research, vol. 40, no. 7, pp. 1060-1071, 2010.

[35] I.-O. Toma, D. Covatariu, A.-M. Toma, G. Taranu, and M. Budescu, "Strength and elastic properties of mortars with various percentages of environmentally sustainable mineral binder," Construction and Building Materials, vol. 43, pp. 348-361, 2013.

[36] Y. Satoh, "Position and load of failure in Brazilian test; A numerical analysis by Griffith criterion," Journal of the Society of Materials Science, Japan, vol. 36, no. 410, pp. 1219-1224, 1987.

[37] V. J. García, C. O. Márquez, A. R. Zúñiga-Suárez, B. C. Zuñiga-Torres, and L. J. Villalta-Granda, "Brazilian test of concrete specimens subjected to different loading geometries: review and new insights," International Journal of Concrete Structures and Materials, vol. 11, no. 2, pp. 343-363, 2017.

[38] X. Jin, C. Hou, X. Fan et al., "Quasi-static and dynamic experimental studies on the tensile strength and failure pattern of concrete and mortar discs," Scientific Reports, vol. 7, no. 1, p. 1, 2017.

[39] W. Gabauer, "The determination of uncertainties in tensile testing. Manual of codes of practice for the determination of uncertainties in mechanical tests on metallic materials," SMT4-CT97-2165, Voestalpine Stahl GmbH, Linz, Austria, 2000.

[40] Joint Committee for Guides in Metrology, JCGM 101: Evaluation of Measurement Data-Supplement 1 to the "Guide to the Expression of Uncertainty in Measurement"-Propagation of Distributions Using a Monte Carlo Method, Joint Committee for Guides in Metrology, Cedex, France, 2008.

[41] B. N. Whittaker, R. N. Singh, and G. Sun, Rock Fracture Mechanics: Principles, Design, and Applications, Elsevier, Amsterdam, Netherlands, 1992.

[42] R. Gutiérrez, M. Ramírez, E. Olmeda, and V. Díaz, "Practical case application for stress model validation and enhancement by means of metrological tools," Strain, vol. 51, no. 5, pp. 379-390, 2015.

[43] T. Hesterberg, "What teachers should know about the bootstrap: resampling in the undergraduate statistics curriculum," 2014, https://arxiv.org/abs/1411.5279.

[44] L. N. G. F., "A treatise on the mathematical theory of elasticity,” Nature, vol. 105, no. 2643, pp. 511-512, 1920.

[45] Micro-Measurements, "Strain gage installations on concrete structures," Tech Tip TT-811, Vishay Precision Group, Malvern, PA, USA, 2015.

[46] Micro-Measurements, "Strain gage installations on concrete structures," Tech Note TN-515, Vishay Precision Group, Malvern, PA, USA, 2015.

[47] ASTM International, ASTM E111-04 Standard Test Method for Young's Modulus, Tangent Modulus, and Chord Modulus, ASTM International, West Conshohocken, PA, USA, 2004.

[48] ASTM International, ASTM E132-04 Standard Test Method for Poisson's Ratio at Room Temperature, ASTM International, West Conshohocken, PA, USA, 2010.

[49] Joint Committee for Guides in Metrology (JCGM), Evaluation of Measurement Data: Guide to the Expression of Uncertainty in Measurement, Joint Committee for Guides in Metrology (JCGM), vol. 120, Cedex, France, 2008. 